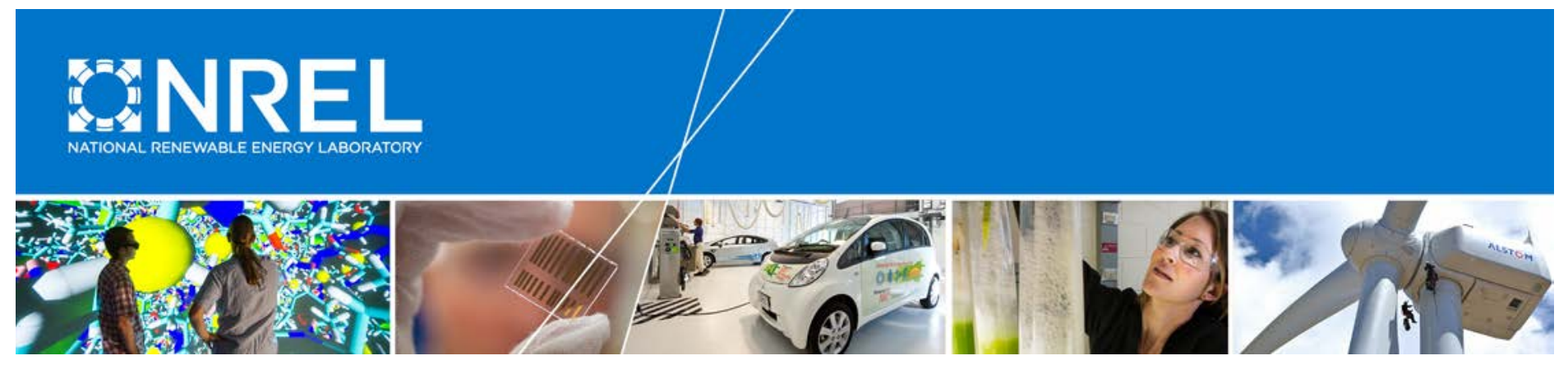

\title{
Evaluating the Technical and Economic Performance of PV Plus Storage Power Plants
}

Paul Denholm, Josh Eichman, and Robert Margolis National Renewable Energy Laboratory

NREL is a national laboratory of the U.S. Department of Energy Office of Energy Efficiency \& Renewable Energy Operated by the Alliance for Sustainable Energy, LLC

This report is available at no cost from the National Renewable Energy Laboratory (NREL) at www.nrel.gov/publications.

Technical Report

NREL/TP-6A20-68737

August 2017

Contract No. DE-AC36-08G028308 


\title{
Evaluating the Technical and Economic Performance of PV Plus Storage Power Plants
}

\author{
Paul Denholm, Josh Eichman, \\ and Robert Margolis \\ National Renewable Energy Laboratory \\ Prepared under Task No. SETP-10304-23.01.10
}

NREL is a national laboratory of the U.S. Department of Energy Office of Energy Efficiency \& Renewable Energy Operated by the Alliance for Sustainable Energy, LLC

This report is available at no cost from the National Renewable Energy Laboratory (NREL) at www.nrel.gov/publications.

National Renewable Energy Laboratory 15013 Denver West Parkway Golden, CO 80401

303-275-3000 • www.nrel.gov

\section{Technical Report}

NREL/TP-6A20-68737

August 2017

Contract No. DE-AC36-08G028308 


\section{NOTICE}

This report was prepared as an account of work sponsored by an agency of the United States government. Neither the United States government nor any agency thereof, nor any of their employees, makes any warranty, express or implied, or assumes any legal liability or responsibility for the accuracy, completeness, or usefulness of any information, apparatus, product, or process disclosed, or represents that its use would not infringe privately owned rights. Reference herein to any specific commercial product, process, or service by trade name, trademark, manufacturer, or otherwise does not necessarily constitute or imply its endorsement, recommendation, or favoring by the United States government or any agency thereof. The views and opinions of authors expressed herein do not necessarily state or reflect those of the United States government or any agency thereof.

This report is available at no cost from the National Renewable Energy Laboratory (NREL) at www.nrel.gov/publications.

Available electronically at SciTech Connect http:/www.osti.gov/scitech

Available for a processing fee to U.S. Department of Energy and its contractors, in paper, from:

U.S. Department of Energy

Office of Scientific and Technical Information

P.O. Box 62

Oak Ridge, TN 37831-0062

OSTI http://www.osti.gov

Phone: 865.576.8401

Fax: 865.576.5728

Email: reports@osti.gov

Available for sale to the public, in paper, from:

U.S. Department of Commerce

National Technical Information Service

5301 Shawnee Road

Alexandria, VA 22312

NTIS http://www.ntis.gov

Phone: 800.553 .6847 or 703.605 .6000

Fax: 703.605.6900

Email: orders@ntis.gov 


\section{Acknowledgments}

The authors would like to thank the following individuals for their contributions. Matt O'Connell, Jennie Jorgenson, and Josh Novacheck generated simulated price data and performed test simulations that inspired this analysis. Conversations with Scott Rackey, Rob van Haaren, and Dirk Weiss at First Solar provided useful insights. Thoughtful reviews and comments were provided by Kate Anderson, Wesley Cole, Tassos Golnas, Kelsey Horowitz, Ran Fu, Becca Jones-Albertus, Mark Mehos, Matt O'Connell, Mike Simpson (AES), and Parikhit (Ricky) Sinha (First Solar). Editing and graphics support were provided by Dean Armstrong, Mike Meshek, and Jarrett Zuboy.

Finally, we gratefully acknowledge funding for this work from the Solar Energy Technologies Office of the U.S. Department of Energy's Office of Energy Efficiency and Renewable Energy under contract number DE-AC36-08GO28308. 


\section{Nomenclature or List of Acronyms}

$\mathrm{AC}$

ATB

$\mathrm{B} / \mathrm{C}$

BOS

CAISO

CT

DC

ILR

ITC

LAP

LCOE

MACRS

MW

MWh

O\&M

NREL

PV

SCE

$\mathrm{T} \& \mathrm{D}$ alternating current

Annual Technology Baseline

benefit/cost (ratio)

balance of system

California Independent System Operator

combustion turbine

direct current

inverter loading ratio

investment tax credit

load aggregation point

levelized cost of electricity

Modified Accelerated Cost Recovery System

megawatt

megawatt-hour

operation and maintenance

National Renewable Energy Laboratory

photovoltaics

Southern California Edison

transmission and distribution 


\section{Executive Summary}

The decreasing costs of both PV and energy storage technologies have raised interest in the creation of combined "PV plus storage" power plants. In this study, we examine the tradeoffs among various PV plus storage configurations and discuss an approach to quantify the impact of configuration on system net value.

We consider the four system configurations listed in Table ES-1.

Table ES-1. PV Plus Storage Configurations

\begin{tabular}{llll}
\hline Type of Coupling & Co-Located? & Point of Common Coupling & Energy Stored \\
\hline Independent & No & None & Grid \\
AC-coupled & Yes & Transmission/feeder & Grid or PV \\
DC-coupled & Yes & DC side of inverter & Grid or PV \\
DC tightly coupled & Yes & DC side of inverter & Only PV \\
\hline
\end{tabular}

We use benefit/cost $(\mathrm{B} / \mathrm{C})$ ratio, measured here by the ratio of the sum of Year 1 energy and capacity value and the Year 1 (levelized) capital and operating costs, as our primary performance metric, as levelized cost of energy does not consider the difference in value between various PV plus storage configurations. Coupling PV and storage can change both the benefits (energy revenue and capacity value) and costs. Coupling PV and storage can increase the revenue by utilizing otherwise clipped energy. Coupling can also decrease revenue by restricting storage operation during periods of high solar output because of the shared inverter. Coupling can also reduce costs by sharing components.

To evaluate these tradeoffs, we consider a case study of different PV plus storage systems located in Southern California. Figure ES-1 shows the results for our base system, which consists of a 50-megawatt (MW) fixed-tilt PV system with an inverter loading ratio of 1.3 and 30 MW/120 megawatt-hours (MWh) of storage. At historical (2014) electricity prices (when PV penetration in California was about 6\%), and 2016 estimated costs for PV and battery components, the $\mathrm{B} / \mathrm{C}$ ratio of $\mathrm{PV}$ without storage is greater than a system with added storage. However, because of the decrease in system capital cost associated with coupling, DC-coupled $\mathrm{PV}$ plus storage systems have higher $\mathrm{B} / \mathrm{C}$ ratios than $\mathrm{PV}$ and storage deployed independently. The plant with the highest $\mathrm{B} / \mathrm{C}$ ratio is the plant that stores only solar due to eligibility for the investment tax credit (ITC). While forcing the plant to store only solar reduces energy revenue, the decrease in cost due to the ITC is greater than the loss in revenue. 


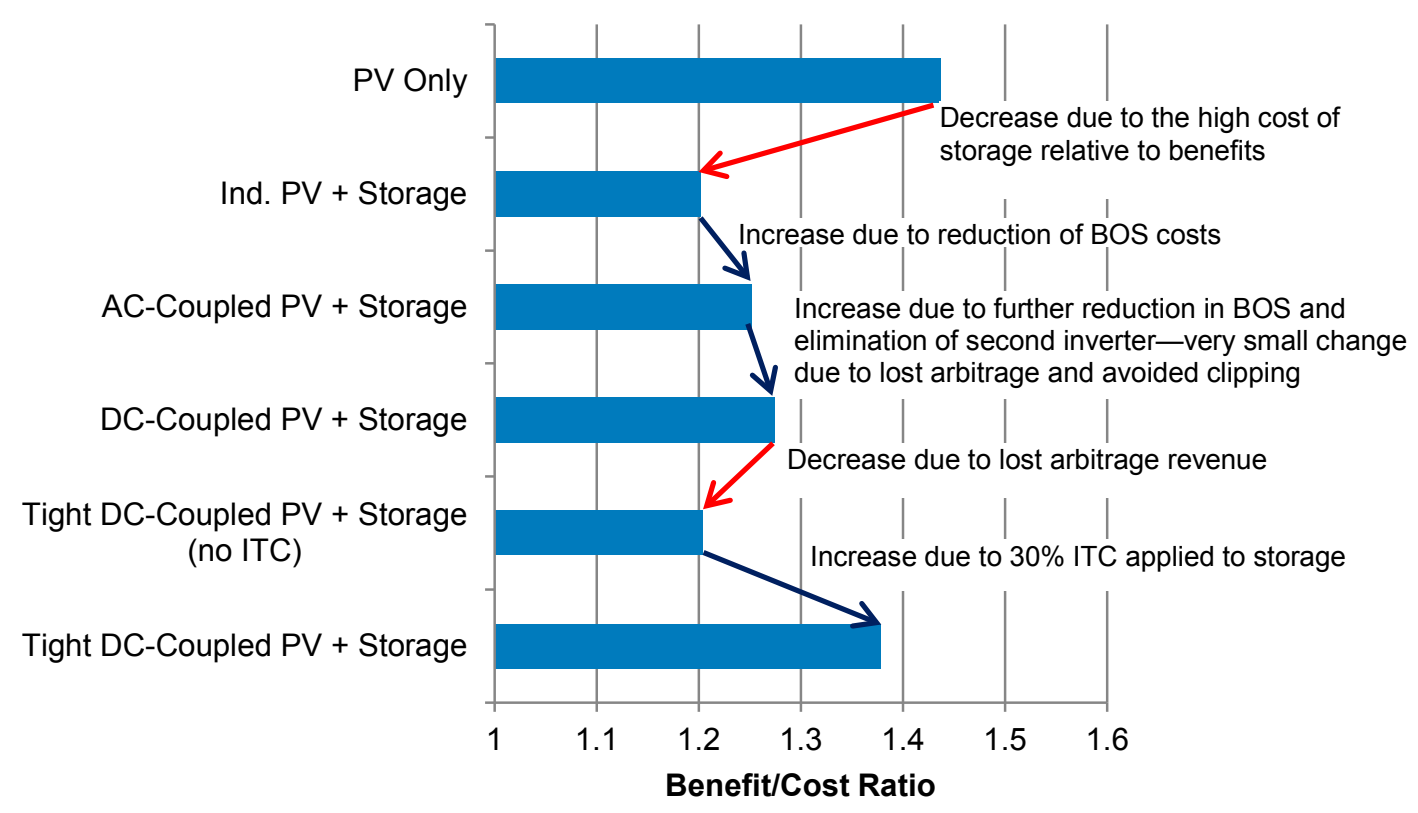

Figure ES-1. Base case B/C ratio for PV plus storage in California using 2014 electricity prices and 2016 estimated PV and battery costs

The projected decrease in battery costs will likely increase the $\mathrm{B} / \mathrm{C}$ ratio of $\mathrm{PV}$ plus storage systems. However, increased PV penetration will decrease its value. Figure ES-2 shows the results for a 2020 case, using projected costs for PV and batteries, as well as simulated electricity prices at higher $\mathrm{PV}$ penetrations $(15 \%$ and $24 \%$ ). At the higher $\mathrm{PV}$ penetration, the $\mathrm{B} / \mathrm{C}$ ratio has fallen below 1 . However, the $\mathrm{B} / \mathrm{C}$ ratio for $\mathrm{PV}$ plus storage systems exceed $\mathrm{PV}$ alone.

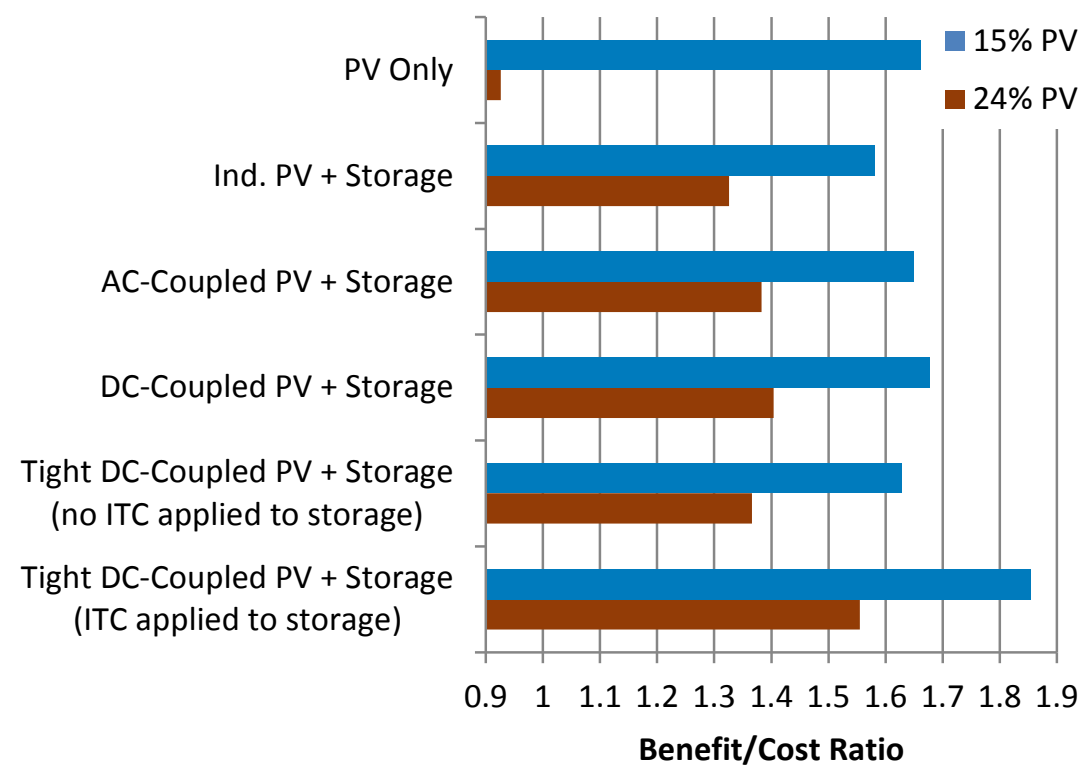

Figure ES-2. B/C Ratio for PV plus storage in California in a 2020 scenario with two different levels of PV penetration and the $30 \%$ ITC 
We also considered cases without the ITC, and while the $\mathrm{B} / \mathrm{C}$ ratio fell, it remained above 1 , demonstrating that projected cost reductions in both PV and storage technologies can help maintain economic competitiveness for PV plus storage at increased penetration levels. While the results presented here are for a very specific set of assumptions, we find that DC-coupling can increase the $\mathrm{B} / \mathrm{C}$ ratio of the PV plus storage systems and with continued cost declines can aid in increasing the economic deployment of PV generation. 


\section{Table of Contents}

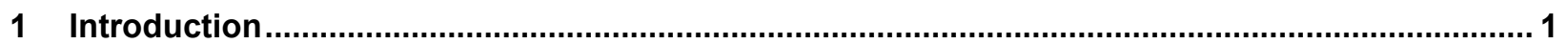

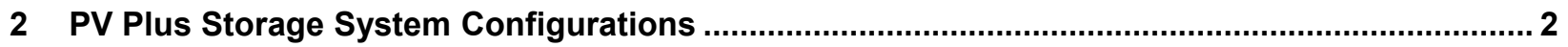

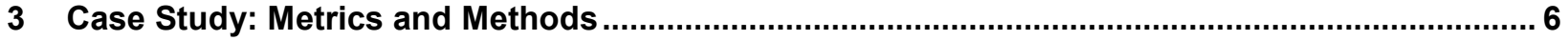

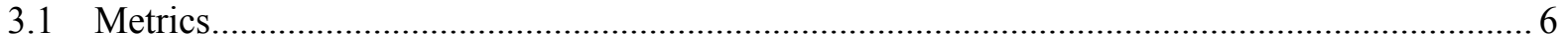

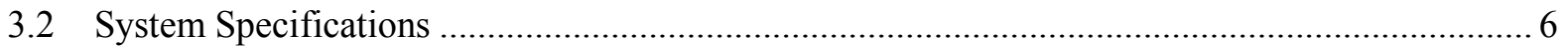

3.3 Calculation of Energy Revenue and Capacity Value …............................................................ 7

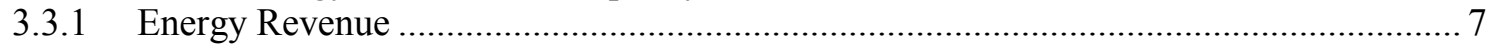

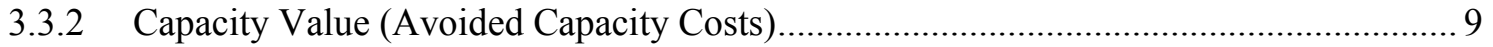

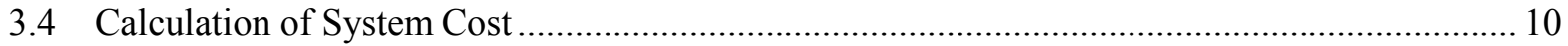

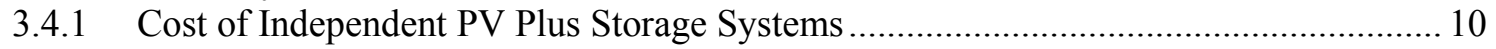

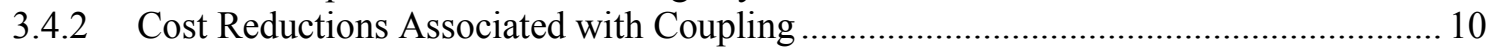

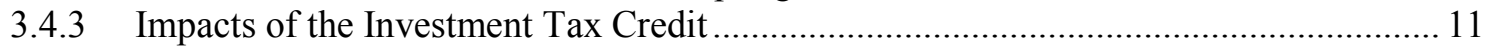

4 Case Study Results: Impact of Configuration on Net Value ........................................................ 12

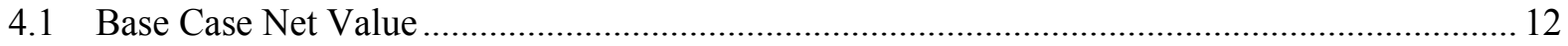

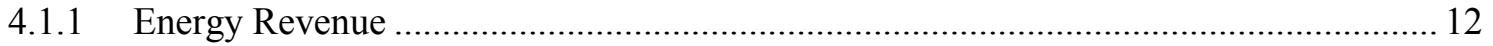

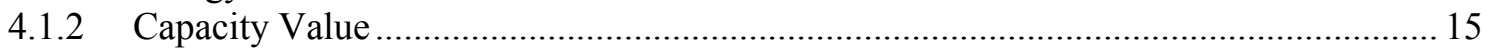

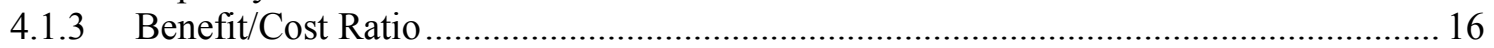

4.2 Impact of Increased PV Penetration and Cost Reductions .................................................. 17

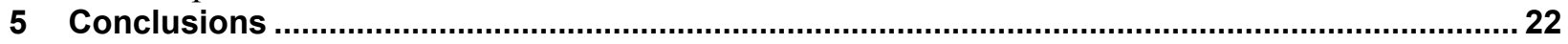

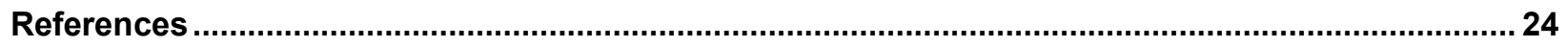

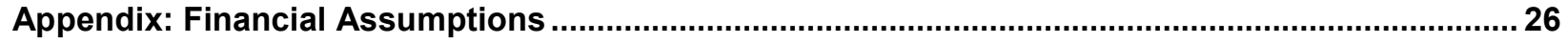




\section{List of Figures}

Figure ES-1. Base case B/C ratio for PV plus storage in California using 2014 electricity prices and 2016 estimated PV and battery costs ........................................................................................... vi

Figure ES-2. B/C Ratio for PV plus storage in California in a 2020 scenario with two different levels of PV penetration and the $30 \%$ ITC vi

Figure 1. Schematic of independent PV plus storage system ....................................................... 3

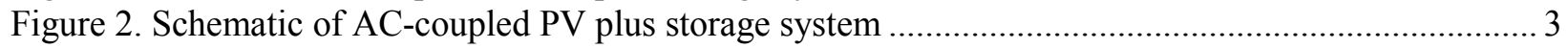

Figure 3. Schematic of DC-coupled PV plus storage systems ...................................................... 4

Figure 4. Current tax incentives for battery systems when combined with PV .................................... 11

Figure 5. Optimal dispatch of energy storage in California using price-taker simulation and 2014 price data from the SCE LAP

Figure 6. Optimal dispatch of a DC-coupled PV plus storage plant on June 16 using 2014 price data from

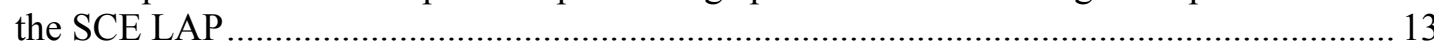

Figure 7. Dispatch of PV plus storage systems on July 1, 6\% PV, 4 hr, 2014 ...................................... 14

Figure 8. Optimal dispatch of a DC tightly coupled PV plus storage system (which stores only PV energy) on June 16 using 2014 price data from the SCE LAP.......

Figure 9. Base case benefit/cost ratio for PV and storage in California using 2014 electricity prices and

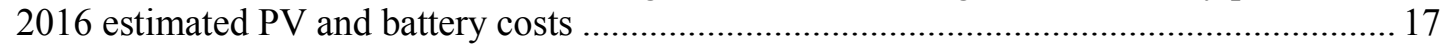

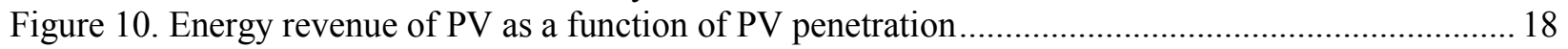

Figure 11. Impact of increased PV penetration on net load in California............................................... 19

Figure 12. Decline in PV capacity credit using the capacity-factor approximation.................................. 19

Figure 13. B/C ratio for PV plus storage plants in a 2020 scenario with two different levels of PV

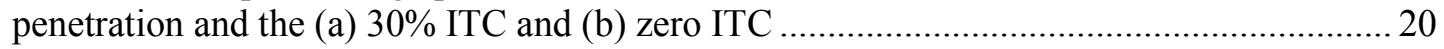

\section{List of Tables}

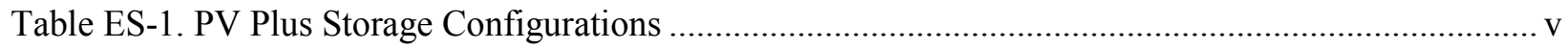

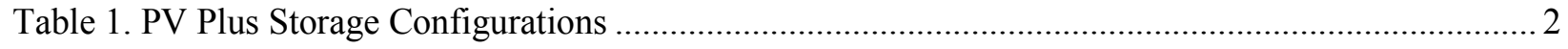

Table 2. Cost and Value Changes Associated with Physical Coupling of PV Plus Storage Systems

Compared to Independently Deployed PV and Storage...................................................... 5

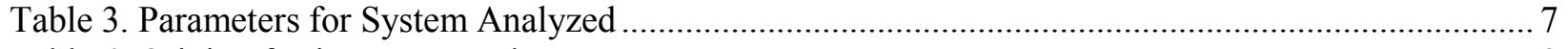

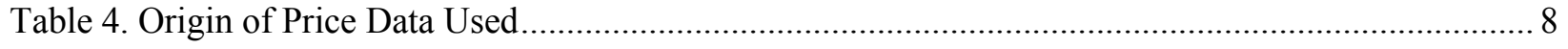

Table 5. Constraints Associated with Physical Coupling for PV Plus Storage System............................ 8

Table 6. Assumed Cost Components for Independent PV (Fixed Tilt, ILR = 1.3) Plus Storage Systems . 10

Table 7. Annualized Cost Components $(\$ / \mathrm{kW})$ for PV Plus Storage Systems ........................................ 10

Table 8. Energy Revenue from PV Plus Storage Systems with an ILR of 1.3, PV AC Rating of 50 MW, and Storage with $30 \mathrm{MW}$ and 4 Hours of Capacity Using SCE 2014 Prices .......................... 15

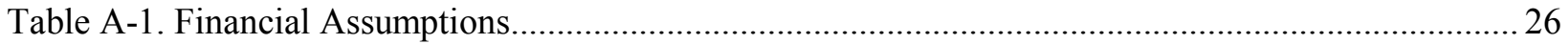




\section{Introduction}

There is growing interest in taking advantage of the declining costs of both PV and energy storage technologies to create combined "PV plus storage" power plants. Yet there has been limited deployment of utility-scale PV plus storage systems, and technical and economic performance metrics for utility-scale PV plus storage systems are not well defined.

To help create a common framework for future discussion and analysis, we explore the technical and economic performance of utility-scale PV plus storage systems. We have three primary goals:

1. Explore the physical configuration of PV plus storage systems and examine the basic technical parameters, including the type and degree of PV/storage "coupling"

2. Identify key metrics useful for evaluating the technical and economic performance of PV plus storage systems

3. Examine the tradeoffs among various PV plus storage configurations and quantify the impact of configuration on system net value.

The report is structured as follows. Section 2 discusses PV plus storage configurations and defines key terminology. Section 3 discusses metrics and methods to evaluate technical and economic performance. Section 4 presents a case study evaluating the impact of configuration on the value of PV plus storage. Section 5 provides conclusions and discusses outstanding issues associated with appropriate valuation of PV plus storage systems. 


\section{PV Plus Storage System Configurations}

In this section, we define and describe PV plus storage systems in terms of the sizing and operation of system components, particularly the degree to which the storage and PV are "coupled" physically and operationally. We consider four system configurations (Table 1).

Table 1. PV Plus Storage Configurations

\begin{tabular}{llll}
\hline Type of Coupling & Co-Located? & $\begin{array}{l}\text { Point of Common } \\
\text { Coupling }\end{array}$ & Energy Stored \\
\hline Independent & No & None & Grid (could include PV via market) \\
AC-coupled & Yes & Transmission/feeder & Grid or PV \\
DC-coupled & Yes & DC side of inverter & Grid or PV \\
DC tightly coupled & Yes & DC side of inverter & Only PV \\
\hline
\end{tabular}

a Although grid-connected storage is typically charged from unspecified off-peak resources, it can "virtually" store energy from a specific source via bilateral market transactions.

Figure 1 provides a schematic of independent PV and storage systems, which represents how the vast majority of U.S. utility-scale PV and storage systems are currently deployed. ${ }^{1}$ These systems are not physically co-located and do not share common components or control strategies. This configuration is used as a point of comparison to coupled systems. As a result of being independent, storage responds to overall grid conditions to provide peak capacity, shift energy from off-peak to on-peak periods, and provide ancillary services. The storage can charge with any grid resource that provides low-cost energy (including off-peak wind, coal, or nuclear power) and discharge during periods of peak demand (typically in the afternoon when energy is most costly). Because the storage is not tied to a single energy source, it can charge from whatever source of energy has the lowest operational cost, which maximizes its value to the grid. Although the storage could charge from PV energy, it would only do so when grid conditions made this an economic option.

\footnotetext{
${ }^{1}$ The country's utility-scale PV produces energy under various contractual agreements, but it is not typically "firmed" or otherwise scheduled beyond the normal weather-driven production. Likewise, most existing U.S. storage (about 21 gigawatts, mostly pumped hydro) is not physically co-located or operationally integrated with PV or any other type of power plant (U.S. Department of Energy, "DOE Global Energy Storage Database" www.energystorageexchange.org/).
} 

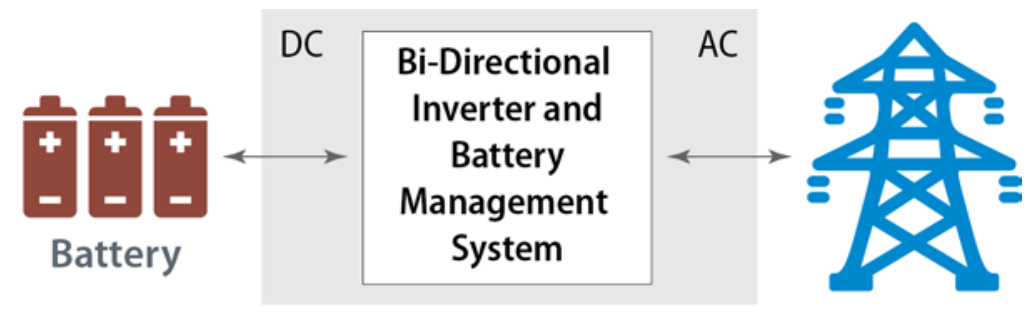

Grid
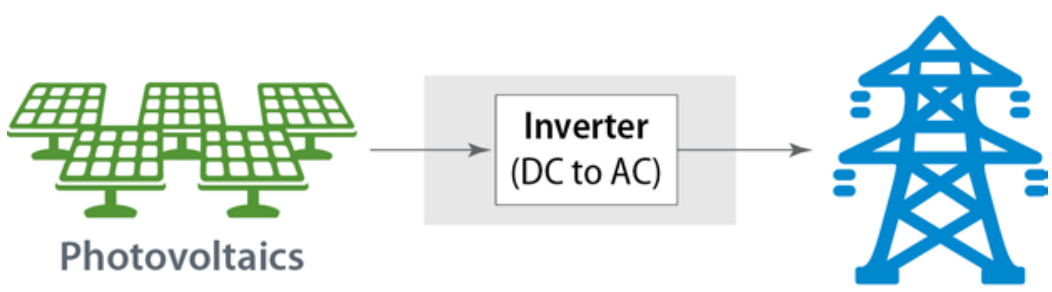

Photovoltaics

Grid

Figure 1. Schematic of independent PV plus storage system

The next two figures show physically coupled system configurations, which currently constitute a very small proportion of the utility-scale PV and storage in the United States. Figure 2 shows AC-coupled systems in which storage and PV are co-located and share a point of common coupling on the AC grid. Because the plant does not share any components, the storage can still act independently of the PV system.

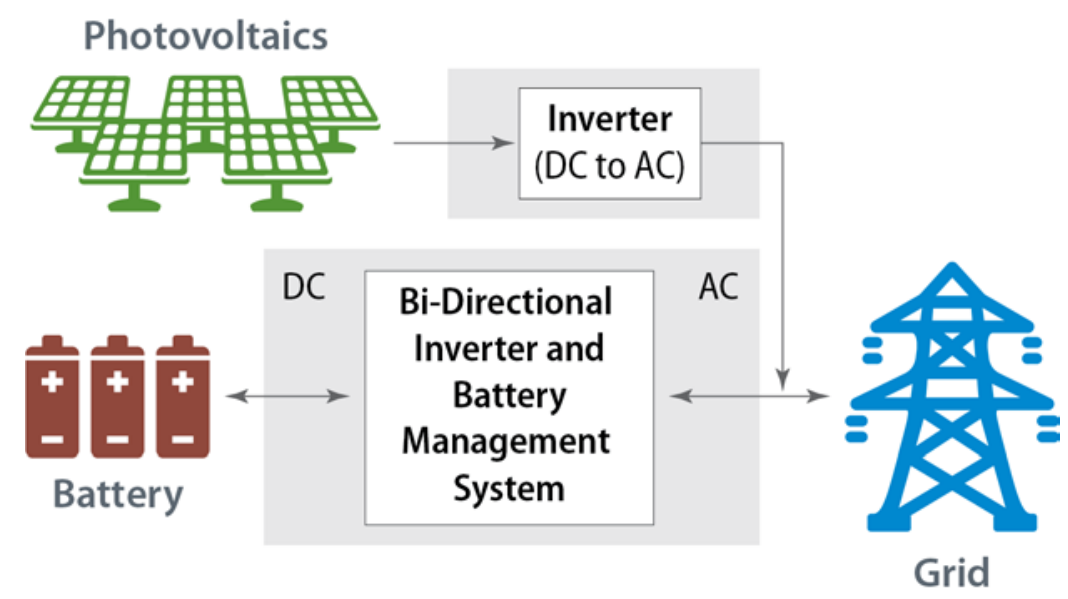

Figure 2. Schematic of AC-coupled PV plus storage system

Figure 3 shows systems in which the PV and storage are coupled on the DC side of a shared inverter. The DC-coupled system (Figure 3[a]) includes a bi-directional inverter that enables the storage to charge from the grid, in addition to charging from the PV. The DC tightly coupled system (Figure $3[\mathrm{~b}]$ ) assumes storage can only store PV electricity, not grid electricity. We include the DC tightly coupled configuration in order to consider the current federal investment tax credit (ITC) in the United States. For the ITC to apply to the full cost of a PV plus storage system, it would need to be operated in a tightly or nearly tightly coupled fashion (Ardani et al. 2017). Thus, understanding the benefits and cost of this system configuration is important from both an operational standpoint and from a policymaking perspective. 


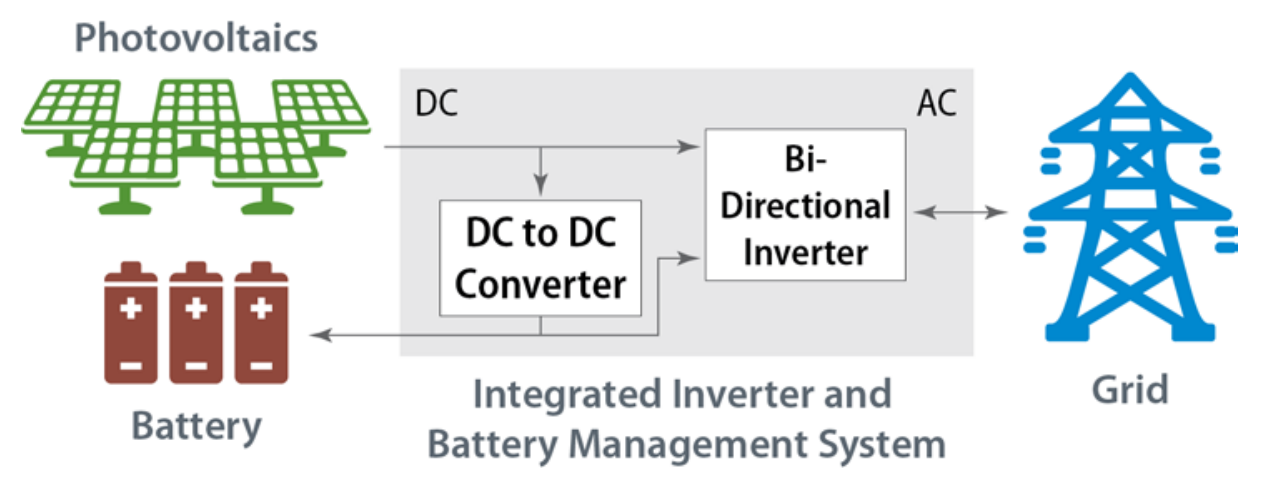

(a) DC-coupled (flexible charging)

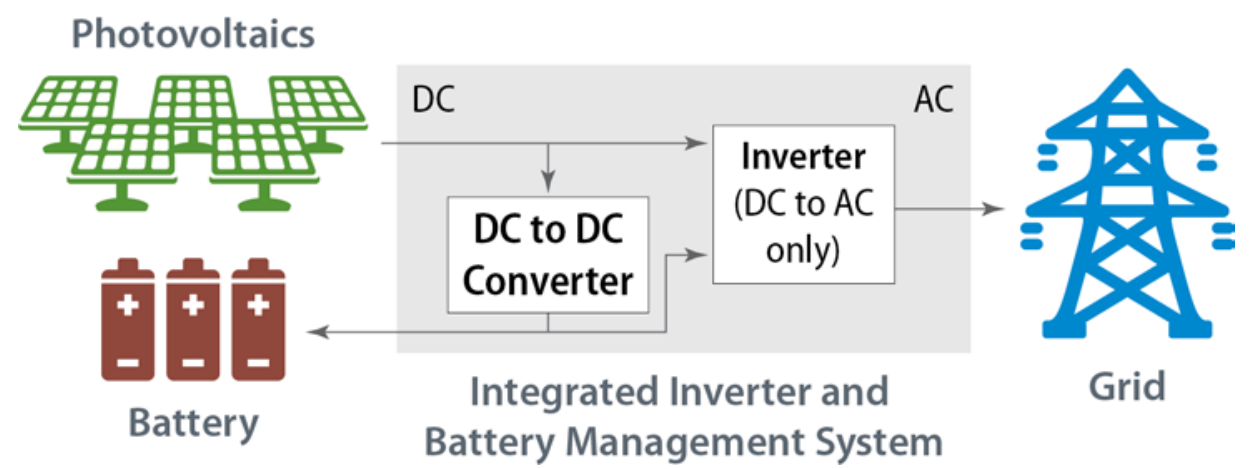

(b) DC tightly coupled (PV-only charging)

Figure 3. Schematic of DC-coupled PV plus storage systems

Qualitatively speaking, progressively greater coupling will change both the value and cost of a PV plus storage system when compared to independently deployed PV and storage. The value can increase because DC coupling allows the system to store otherwise clipped energy that occurs when the inverter loading ratio exceeds 1 (discussed in Section 3.2). Alternatively, both the capacity value and energy value of the system can decline because coupling decreases the operational flexibility of the combined plant's storage component. Costs decline because of the potential to share balance-of-system (BOS) costs. Table 2 summarizes the qualitative value and cost tradeoffs that affect the net value proposition for each PV plus storage system. The remainder of this report uses a case study of a PV system in southern California to quantify these tradeoffs and determine whether the coupling-related change in each system's value outweighs the coupling-related change in costs. 
Table 2. Cost and Value Changes Associated with Physical Coupling of PV Plus Storage Systems Compared to Independently Deployed PV and Storage

\begin{tabular}{|c|c|c|c|}
\hline \multirow{2}{*}{$\begin{array}{l}\text { Type of } \\
\text { Coupling }\end{array}$} & \multicolumn{2}{|c|}{ Change in Value (Relative to Independent System) } & \multirow{2}{*}{$\begin{array}{l}\text { Change in Cost (Relative } \\
\text { to Independent) }\end{array}$} \\
\hline & Energy Revenue & Capacity Value & \\
\hline$A C$ & $\begin{array}{l}\text { Potentially lower value because it cannot } \\
\text { be sited in regions with higher } \\
\text { congestion-related prices } \\
\text { Higher losses when storing grid energy } \\
\text { (due to additional transmission losses) }^{a}\end{array}$ & None & Reduction in BOS costs $^{\mathrm{b}}$ \\
\hline $\begin{array}{l}\text { DC (flexible } \\
\text { charging) }\end{array}$ & $\begin{array}{l}\text { Storage operation constrained by shared } \\
\text { inverter } \\
\text { Potentially higher losses when storing } \\
\text { grid energy } \\
\text { Can store clipped solar that occurs due } \\
\text { to ILR>1 } \\
\text { Lower losses when storing solar }^{d}\end{array}$ & Limited to inverter capacity & $\begin{array}{l}\text { Reduction in BOS costs Reduction in } \\
\text { power electronics costs due to shared } \\
\text { inverter }\end{array}$ \\
\hline $\begin{array}{l}\text { DC_tight (PV } \\
\text { only charging) }\end{array}$ & $\begin{array}{l}\text { Same as DC-coupled flexible charging }+ \\
\text { Storage cannot charge from low-cost grid } \\
\text { energy }\end{array}$ & $\begin{array}{l}\text { Same as DC-coupled flexible charging + } \\
\text { Cannot charge with grid energy to ensure } \\
\text { full capacity value }\end{array}$ & $\begin{array}{l}\text { Same as DC-coupled flexible charging + } \\
\text { Small (if any) reduction in battery } \\
\text { management system cost }\end{array}$ \\
\hline
\end{tabular}

${ }^{a}$ Assuming independent storage is sited closer to load and incurs lower loss rates; this change is not considered in this study; the case also assumes the transmission capacity equals the sum of the PV and inverter ratings.

${ }^{\mathrm{b}}$ Includes interconnection, permitting, overhead, engineering, labor, and land costs

${ }^{c}$ Due to remote location when compared to storage sited in a load center (Nourai et al. 2008)

${ }^{d}$ Not considered in this study 


\section{Case Study: Metrics and Methods}

In this section, we discuss metrics that can be used to evaluate the economic performance of solar plus storage configurations. We also introduce the systems analyzed for our case study and describe our calculations of value and cost.

\subsection{Metrics}

Many analyses of new generation technologies focus on costs and cost minimization. Levelized cost of energy (LCOE) is probably the most widely used metric for discussing the costs of electricity generation, owing to its simplicity, historical use, and clear definition. Applying LCOE to a PV plus storage system that stores only PV is relatively simple (Lai and McCulloch 2016). However, LCOE does not consider a generation resource's benefits. The LCOE from a PV plus storage system will always be higher than a system without storage because storage adds costs to the system. However, the addition of storage also provides additional benefits that can outweigh the increase in costs. Such benefits include the value of firm capacity and the ability of a dispatchable generator to produce energy when it is most valuable.

In this report, we evaluate the economic performance of solar plus storage configurations by considering each system's benefit/cost $(\mathrm{B} / \mathrm{C})$ ratio defined as dividing the annualized benefits (energy revenue and capacity value) by the annualized costs (capital and operating). The following subsections describe the analytical methods we use to compare systems in our case study.

\subsection{System Specifications}

We begin by defining a base case PV system located in Southern California $\left(34^{\circ} 51^{\prime} \mathrm{N}\right.$ $\left.117^{\circ} 39^{\prime} \mathrm{W}\right)$. Hourly PV profiles for this system were generated using the System Advisor Model $^{2}$ for a fixed-tilt system with an $\mathrm{AC}$ rating of 50 megawatts (MW). We chose an inverter loading ratio (ILR) of 1.3, which is equal to the average for utility-scale PV systems installed in 2015 (Bolinger and Seel 2016). The ILR is a measure of the PV system size relative to the inverter power rating. The ILR is also called the $\mathrm{DC}$-to- $\mathrm{AC}$ ratio, where $\mathrm{DC}$ refers to the $\mathrm{DC}$ module capacity and $\mathrm{AC}$ refers to the inverter $\mathrm{AC}$ rating. If the inverter is sized to the rating of the $\mathrm{PV}$ array, the inverter will rarely be used at full capacity owing to losses and the relatively few hours of peak PV production. Typically, the PV power rating is made higher than the inverter rating, so the ILR is greater than one. This increases inverter utilization and decreases the system's LCOE up to an ILR of about 1.3-1.4. With an increased ILR, because the PV module can produce more energy than can be used by the inverter, some of the PV energy may need to be curtailed ("clipped"). In our base system, about $0.7 \%$ of potential PV generation is curtailed. In future research, we will explore how storage can use otherwise-clipped energy and potentially enable even higher ILRs.

\footnotetext{
${ }^{2}$ National Renewable Energy Laboratory, System Advisor Model, Version 2016.3.14 (SAM 2016.3.14). The SAM PV model used was PVWatts, assuming a combined loss rate of $13.2 \%$
} 
Table 3 summarizes the analyzed system. The PV system has an AC rating of $50 \mathrm{MW}$ with a module (DC) rating of $65 \mathrm{MW} .{ }^{4}$ The storage power capacity assumes $30 \mathrm{MW}$ of both charge and discharge capacity measured on the AC side of the inverter. We assume 4.0 hours of usable discharge capacity (120 MWh), again measured on the AC side of the inverter, which requires 4.7 hours of charging for a full charge assuming an $85 \%$ round trip efficiency. For each of the four configurations analyzed, we calculate the system's energy revenue and capacity value (Section 3.3) as well as costs (Section 3.4).

Table 3. Parameters for System Analyzed

\begin{tabular}{ll}
\hline Parameter & Value \\
\hline PV system size & $65 \mathrm{MW}$ DC \\
PV orientation & South facing, fixed at 20 degree tilt \\
Inverter size & $50 \mathrm{MW}$ AC (ILR = 1.3) \\
Storage power capacity & $30 \mathrm{MW} \mathrm{AC}$ \\
Storage energy capacity & 4 hours (120 MWh AC) \\
Storage efficiency & $85 \%(\mathrm{AC}-\mathrm{AC})$ \\
\hline
\end{tabular}

\subsection{Calculation of Energy Revenue and Capacity Value}

Here we describe how we calculate energy revenue and capacity value for each system.

\subsubsection{Energy Revenue}

Estimating (and maximizing) the energy revenue of a PV plus storage system requires understanding when the storage will charge and discharge, and knowing the associated cost of energy from charging and discharging. It also requires determining how often (if ever) the device should charge from PV energy, which represents a major issue when evaluating any reduction in value due to forcing a DC-coupled system to store PV energy. This typically requires detailed simulations over an extended period of operation under various conditions.

We calculate the optimal dispatch and value of a marginal addition of solar plus storage system using NREL's RODeO (Revenue, Operation, and Device Optimization) model (Eichman et al. 2016). RODeO is a "price taker" optimization model written in the General Algebraic Modeling System language, which solves a mixed integer linear programming problem to maximize the achievable revenue for generators, flexible load, and storage devices. As used in this study, the modeled system is subject to several constraints, including inverter rating, storage energy capacity, and storage conversion efficiency.

\footnotetext{
${ }^{4}$ The actual physical size of the plant does not change the $\mathrm{B} / \mathrm{C}$ ratio results of this analysis, because we use a pricetaker approach that assumes the value per installed unit of capacity does not vary. The actual impact of greater PV deployment is considered in Section 4.2.
} 
Price-taker models are used to estimate revenue and operation under fixed price scenarios. They thus rely on externally generated prices and are not used by themselves to estimate the value of devices under changing grid mixes. These models typically use either historical prices or simulated price data generated from a production cost model. Here we use a combination of both types of data. Additional discussion of price-taker approaches to simulating the value of storage is provided by Sioshansi et al. (2008).

We calculate revenue for two different scenarios. Our base case uses 2014 price data from the Southern California Edison (SCE) load aggregation point (LAP). In 2014, the penetration of PV was about $6 \% .{ }^{5}$ We also conduct a set of sensitivity cases to estimate the value of PV in a future year (2020) with two different PV penetration levels (15\% and 24\%). For these sensitivity cases we use hourly prices from a previous study that were generated using the PLEXOS production cost model (Denholm et al. 2016). Table 4 summarizes the data sources used in our analysis.

Table 4. Origin of Price Data Used

\begin{tabular}{lll}
\hline Scenario & PV Penetration & Electricity Price Data Source \\
\hline $\begin{array}{l}\text { Base Case (Recent price and } \\
\text { cost data) }\end{array}$ & $6 \%$ & 2014 CAISO day-ahead market prices (SCE LAP) \\
& $\begin{array}{l}\text { Simulated from PLEXOS day-ahead marginal } \\
\text { cost. Database from NREL Low-Carbon Grid }\end{array}$ \\
2020 (sensitivity case) & $15 \%$ and 24\% & $\begin{array}{l}\text { Study (Brinkman et al 2016). Weather year for } \\
\text { that study is 2006, so PV simulations used } \\
2006 \text { data. }\end{array}$ \\
\hline
\end{tabular}

We modified the RODeO model to consider different types of solar plus storage systems, with the additional operational constraints associated with different types of coupling. Table 5 shows the charging and discharging constraints imposed by coupling, which could affect revenue.

Table 5. Constraints Associated with Physical Coupling for PV Plus Storage System

\begin{tabular}{|c|c|c|}
\hline Type of Coupling & $\begin{array}{l}\text { Effective Impact on Storage } \\
\text { Discharge }\end{array}$ & Storage Charge Constraint \\
\hline $\begin{array}{l}\text { Independent } \\
\text { (roughly equivalent to AC- } \\
\text { coupled) }\end{array}$ & None & None \\
\hline DC-coupled & $\begin{array}{l}\text { Maximum discharge }=\text { inverter } \\
\text { rating minus } P V \text { output }\end{array}$ & $\begin{array}{l}\text { If } P V \text { output is greater than } \\
\text { inverter rating (due to ILR }>1 \text { ), } \\
\text { then forced to store solar energy }\end{array}$ \\
\hline DC tightly coupled & $\begin{array}{l}\text { Maximum discharge }=\text { inverter } \\
\text { rating minus PV output }\end{array}$ & Can only charge with PV \\
\hline
\end{tabular}

We assume a roundtrip battery efficiency of $85 \%$ for both directly stored PV and stored grid energy. DC-coupled storage might have a higher net efficiency, particularly when storing PV energy (Ardani et al. 2017). Alternatively, independent storage - unlike storage coupled to a utility-scale PV plant — might be located closer to the load site and thus avoid transmission and

\footnotetext{
${ }^{5}$ This estimate is based on 12.6 terawatt-hours of utility-scale solar (PV and concentrating solar power) generation (CEC 2014) and 5.1 terawatt-hours from rooftop PV (GTM 2015).
} 
distribution (T\&D) losses (Nourai et al 2008). Because determining the actual net efficiency for stored energy would require a detailed analysis of power flow on the T\&D system, we assume a uniform efficiency for all stored energy in this study.

For each scenario, we calculate annual net energy revenue and add this value to the capacity value, which is discussed in the following subsection.

\subsubsection{Capacity Value (Avoided Capacity Costs)}

One of the main arguments for incorporating energy storage with PV is to increase PV's ability to replace or defer capital investments in conventional generation capacity. Following Mills and Wiser (2012a), we use the term "capacity credit" to represent physical capacity, and we use the term "capacity value" to represent the monetary value of this capacity. Capacity credit is the actual fraction of the generators' capacity that could reliably be used to offset conventional capacity, which is typically measured as a value (such as $\mathrm{kW}$ ) or percentage of nameplate rating. Achieving a high capacity credit with PV plus storage requires evaluating the capacity credit of PV alone as well as determining how much storage (both power and energy) must be added to achieve an increased capacity credit.

There is considerable literature on methods to estimate generation capacity credit, and several studies determine capacity credit for PV in different regions (Madaeni et al. 2013a; Mills and Wiser 2012b) and for energy storage (Sioshansi et al. 2014; PGE 2016). The various approaches to estimating capacity credit differ in complexity (Amelin 2009; NERC 2011). However, they generally assess the probability of a plant being available during periods of highest net demand, which is typically during hot summer afternoons throughout most of the United States. Previous analysis has demonstrated that, at very low penetration in the Western United States, PV-even without storage - tends to have a relatively high capacity credit owing to the inherent coincidence of PV supply with summer demand (Mills and Wiser 2012b). This capacity credit drops rapidly as a function of PV penetration, for reasons detailed in Section 4.2.

For a PV plus storage system, the storage increases the system's net capacity credit by supplementing the PV output during periods of high net demand. The capacity credit of the storage system can be measured in a manner similar to measurement of the PV plant, by evaluating the power and energy capacity during the hours of peak net demand.

The overall capacity credit of the PV plus storage system can be translated into a monetary value, often by using the cost of a proxy resource such as a peaking combustion turbine. For example, one estimate of the annualized financing and operations and maintenance (O\&M) cost of a new combustion turbine in California is about $\$ 149 / \mathrm{kW}$ (CAISO 2017). The annualized cost of new capacity establishes a value per kilowatt of firm capacity provided by a PV plus storage system. If we assume the 50-MW PV plant has a 40\% capacity credit, and we add a $30-\mathrm{MW}$ storage plant with $100 \%$ capacity credit, the resulting system can avoid the construction of a 50MW peaking plant. If we assume a conventional plant has an annualized cost of $\$ 149 / \mathrm{kW}$, the PV plus storage plant has a capacity value of $\$ 7.5$ million/year. 


\subsection{Calculation of System Cost}

Here we first describe how we calculate costs for independent PV plus storage systems and then how we calculate cost reductions associated with coupled systems.

\subsubsection{Cost of Independent PV Plus Storage Systems}

We explore two cost scenarios: a scenario based on recent (2016) estimated costs and a sensitivity based on projected 2020 costs (Table 6). PV costs are derived from the 2017 NREL Annual Technology Baseline (ATB). ${ }^{6}$ Storage costs for 2016 and 2020 are from GTM (2016).

Table 6. Assumed Cost Components for Independent PV (Fixed Tilt, ILR = 1.3) Plus Storage Systems

\begin{tabular}{lll}
\hline Component & 2016 Cost & 2020 Cost \\
\hline PV system & $\$ 1,343 / \mathrm{kW}(\mathrm{DC})$ & $\$ 912 / \mathrm{kW}(\mathrm{DC})$ \\
PV (O\&M) & $\$ 12 / \mathrm{kW}-\mathrm{yr}$ & $\$ 11 / \mathrm{kW}-\mathrm{yr}$ \\
Battery module & $\$ 304 / \mathrm{kWh}$ & $\$ 217 / \mathrm{kWh}$ \\
Battery BOS & $\$ 612 / \mathrm{kW}$ & $\$ 398 / \mathrm{kW}$ \\
Battery O\&M & $\$ 9 / \mathrm{kW}-\mathrm{yr}$ & $\$ 9 / \mathrm{kW}-\mathrm{yr}$ \\
\hline
\end{tabular}

\subsubsection{Cost Reductions Associated with Coupling}

A key motivation for co-locating storage with $\mathrm{PV}$ is the potential to realize cost reductions. An AC-coupled system shares little hardware, but costs associated with engineering, customer and site acquisition, permitting, and labor can potentially be shared. For a DC-coupled system, the second inverter can be eliminated, further reducing costs. Because PV plus storage plants have not yet been deployed on a large scale, estimating the actual reduction in cost is difficult.

Table 7 summarizes our assumptions for cost reductions associated with coupling. The reduction in cost for the AC-coupled system is based on our estimates of the fraction of base BOS costs (values in Table 6) that can be avoided from combining PV and storage at a single site. For DC coupled system we eliminate the estimated costs of PV inverters in 2016 and 2020 (Fu et al. 2017).

Table 7. Assumed Avoided Cost of Battery BOS (\$/kW) Associated with Coupling

\begin{tabular}{lcc}
\hline Type of Coupling & \multicolumn{2}{c}{ Avoided Cost (\$/kW) } \\
\hline & $\mathbf{2 0 1 6}$ & $\mathbf{2 0 2 0}$ \\
AC-Coupled System & $\$ 161(26 \%)$ & $118(30 \%)$ \\
DC-Coupled System & $\$ 221(36 \%)$ & $158(40 \%)$ \\
Tight DC-Coupled System & \multicolumn{2}{c}{ Same as DC-Coupled }
\end{tabular}

\footnotetext{
${ }^{6}$ Available at www.nrel.gov/analysis/data tech_baseline.html; Values used are from the forthcoming 2017 version of the ATB.
} 


\subsubsection{Impacts of the Investment Tax Credit}

Current tax rules allow for a 30\% investment tax credit for PV. The ITC falls, starting in 2020 with the amount of decline and timing depending on when the project is begun and placed into service. ${ }^{7}$ For the sake of simplicity, we consider a $30 \%$ ITC case for the base case and we consider both the full $30 \%$ ITC and a zero ITC case for the 2020 scenarios.

Storage is also eligible for a tax credit when combined with PV. As shown in Figure 4, the ability of developers to utilize the ITC for the storage-related components of a combined PV plus storage system depends on the fraction of battery charging by PV. The system must be tightly coupled (charging only with PV energy) to gain full advantage of the ITC. In our DC-coupled case, we evaluate two operational regimes: (1) a DC-coupled system with optimal charging from the grid or PV and (2) a tightly coupled system (battery charged by PV 100\%). In reality, project developers will evaluate the degree of coupling that makes sense on a project by project basis. The tightly coupled case provides the least amount of flexibility in terms of optimized charging; however, from a project level, these losses may be offset by the benefits of being able to apply the ITC to the cost of the storage system.

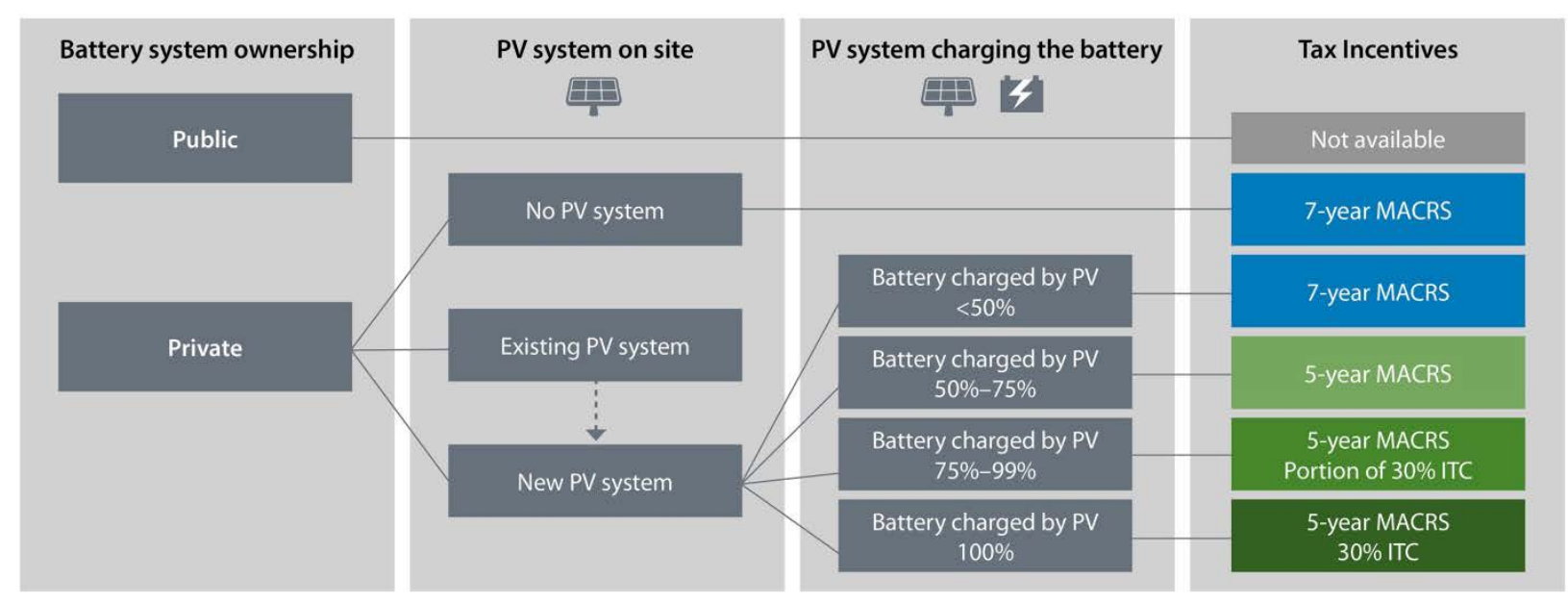

Figure 4. Current tax incentives for battery systems when combined with PV

NREL 2017

To derive a Year 1 (levelized) cost for the various PV plus storage configurations, we use financing terms from the NREL ATB; details are provided in the appendix.

\footnotetext{
${ }^{7}$ See DSIRE, “Business Energy Investment Tax Credit (ITC),” programs.dsireusa.org/system/program/detail/658
} 


\section{Case Study Results: Impact of Configuration on Net Value}

For each system configuration, we determine the energy revenue and capacity value and we incorporate system costs to determine the system's benefit-to-cost ratio.

\subsection{Base Case Net Value}

We begin by providing the results for a limited set of scenarios to demonstrate the framework for our analysis. Our initial case has an ILR of 1.3 and a storage system with $30 \mathrm{MW}$ and 4 hours of capacity. We use the 2014 SCE prices for our base region, with $6 \%$ PV penetration.

\subsubsection{Energy Revenue}

Figure 5 gives an example of how the RODeO model estimates value, showing the optimized charging and discharging of an independent 30-MW storage plant over two 1-day periods. Figure 5(a) shows a summer day (June 16) with the battery charging in early morning, when prices are lowest, and discharging at maximum during the late afternoon and early evening, when prices are highest. The winter dispatch on January 2 (Figure 5[b]) is different, because winter demand tends to have a smaller peak in the morning and a larger peak in the early evening. As a result, the storage plant discharges twice per day, and - although it still mostly charges at night and in the early morning - it also charges during midday.

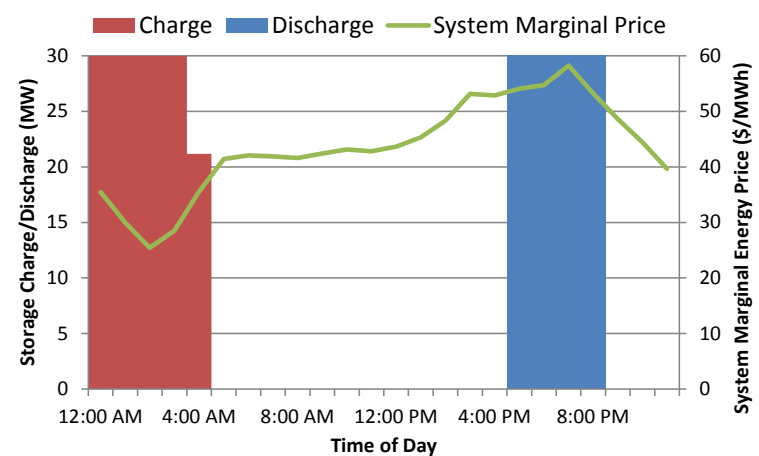

(a) Summer (June 16)

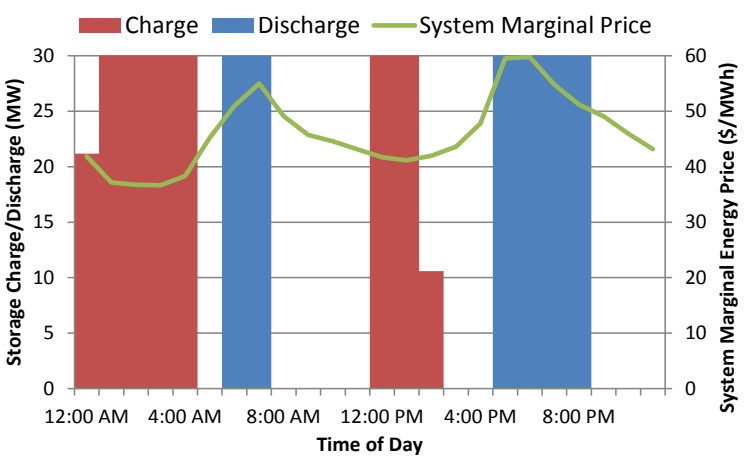

(b) Winter (January 2)

Figure 5. Optimal dispatch of energy storage in California using price-taker simulation and 2014 price data from the SCE LAP

The net revenue for this plant is calculated by multiplying the hourly price $(\$ / \mathrm{MWh})$ by the quantity of energy purchased or sold. In this example, the purchased energy on June 16 (141 MWh) has a total cost of $\$ 4,336$, and the sold energy (120 MWh) has a total revenue of $\$ 6,608$ - giving a net revenue of $\$ 2,272$. The PV energy revenue is simply the hourly PV output multiplied by the hourly price. For comparison, the revenue for the 50-MW solar plant on June 16 is $\$ 19,173$, or about eight times that of the storage plant. The PV revenue on January 2 is $\$ 12,374$ (which is lower than the summer day because the PV output is lower and prices are also lower in the middle of the day), while the storage revenue is $\$ 1,655$. 
Moving to the DC-coupled system changes the operation of the storage plant relative to the independent storage case in two ways. First, storage can avoid the small amount of clipped energy due to the ILR of 1.3. Figure 6 shows the dispatch of the DC-coupled system on the same summer day as shown for the storage-only case in Figure 5(a). The figure shows how the storage is used to store a small amount of energy that would have been clipped because the PV system output exceeds $50 \mathrm{MW}$. The small amount of discharge that occurs before noon occurs to make room for the clipped PV energy (which has zero cost). Without storage, about $2 \%$ of the potential PV energy would have been clipped on this day. This is avoided by using storage, and overall, the revenue of the DC-coupled system is about $1 \%$ higher on this day than it is with the independent PV plus storage system.

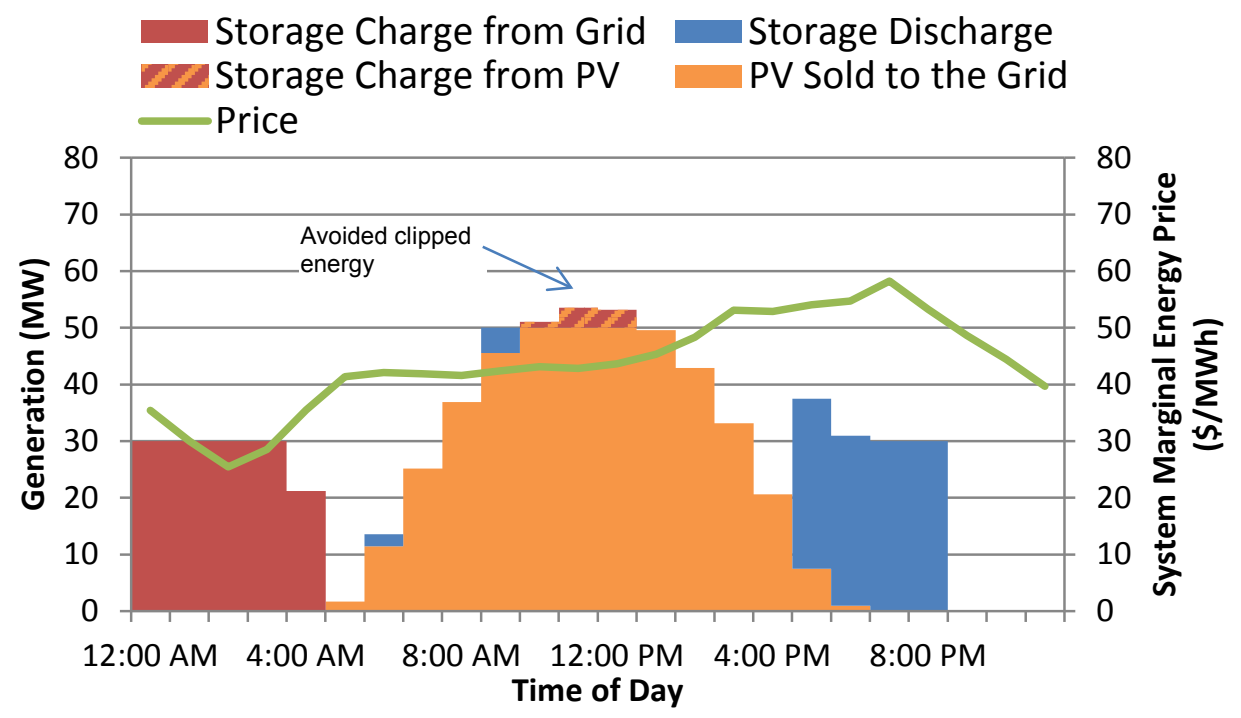

Figure 6. Optimal dispatch of a DC-coupled PV plus storage plant on June 16 using 2014 price data from the SCE LAP

Alternatively, there are other periods in which the storage plant cannot be fully utilized because of the operation of the PV system. This is illustrated in Figure 7, which shows the output of the independent and DC-coupled systems on July 1. Figure 7(a) shows the output of the independent system. It shows that the storage plant discharges at full capacity during the afternoon while there is still considerable solar output. The combined output of the PV and storage plant is as high as $70 \mathrm{MW}$, which is possible because the systems are independent and have separate inverters. However, the DC-coupled system, with a shared 50-MW inverter cannot fully utilize the storage system, resulting in the dispatch shown in Figure 7(b). From 2 pm to 4 pm, the PV system is generating between 30 and $40 \mathrm{MW}$, leaving only 10MW to $20 \mathrm{MW}$ of "spare" inverter capacity. The storage plant is forced to shift output slightly compared to the independent storage system, discharging a small amount of energy either earlier or later in the day when prices are slightly lower. Overall, on this day the DC-coupled system loses about $1 \%$ of its potential value compared to the independent system. As a result, the DC-coupled system produces less revenue than the independent system, and the total revenue of the DC-coupled system on this day $(\$ 30,300)$ is about $\$ 700$ less than the independent system’s revenue. 


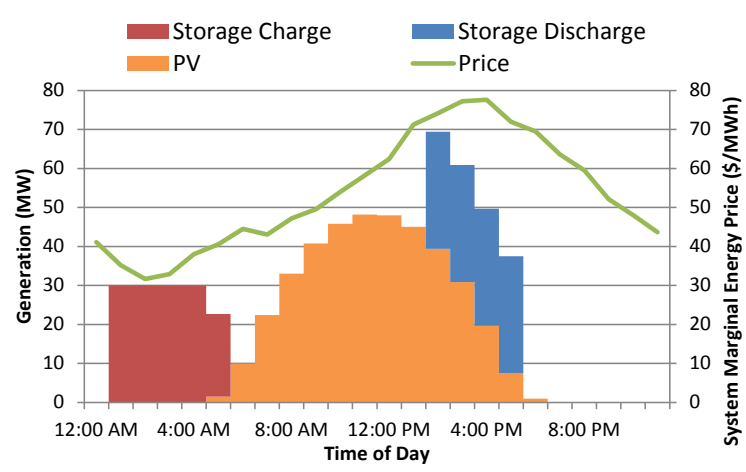

(a) Independent

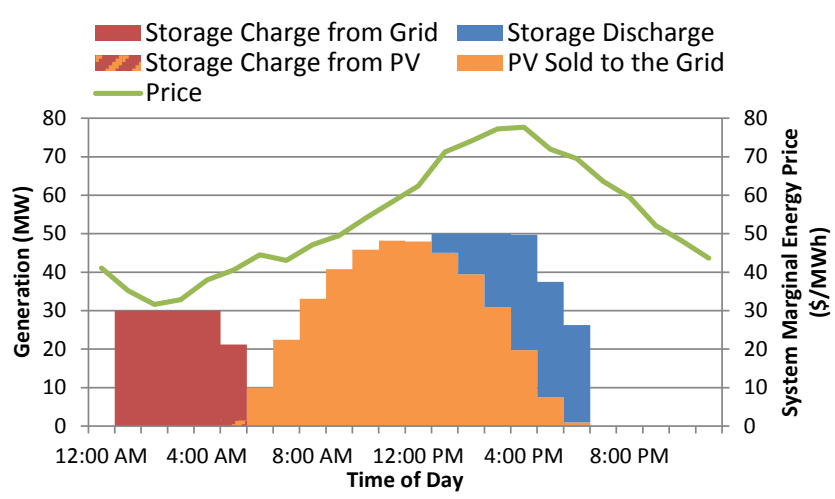

(b) DC-coupled

Figure 7. Dispatch of PV plus storage systems on July 1, 6\% PV, 4 hr, 2014

Price data are from the SCE LAP.

While the impact of DC-coupling compared to independent systems is small, the impact of tightly coupled storage systems (forced to storage only solar) is more significant. Figure 8 shows the results for the DC tightly coupled system that only charges from PV on July 1. Figure 8(a) shows how, by forcing the storage to charge with PV, the system effectively charges with more expensive energy from the middle of the day. The charging pattern can be compared to that in Figure 7, where storage is charged from the grid between $1 \mathrm{a} . \mathrm{m}$. and $5 \mathrm{a} . \mathrm{m}$. where prices are below $\$ 35 / \mathrm{MWh}$. The DC tightly coupled system is forced to store energy when prices are well above $\$ 40 / \mathrm{MWh}$. Figure 8 (b) also shows that, because the tightly coupled system must store PV energy that could have otherwise been sent to the grid, its overall capacity factor is reduced, having effectively "lost" the opportunity to directly sell the energy in the light orange shaded area. On this day, the tightly coupled system's total revenue is $\$ 25,832$, compared to $\$ 27,841$ for the DC-coupled system, representing a loss of $\$ 2,009$, or about $7 \%$.

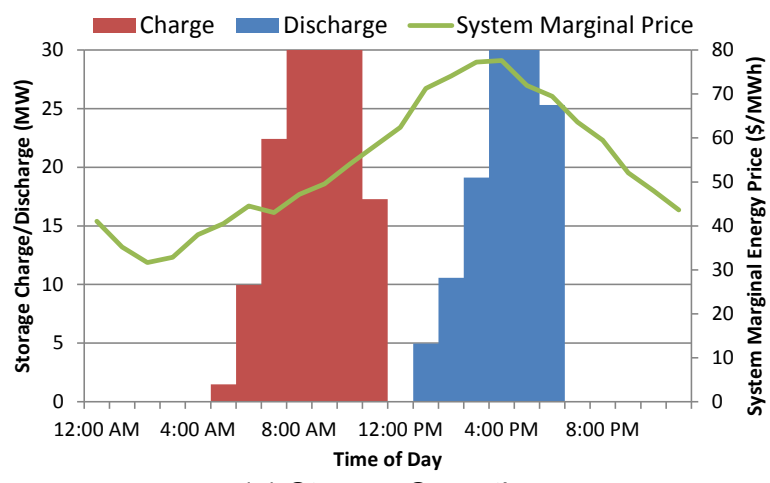

(a) Storage Operation

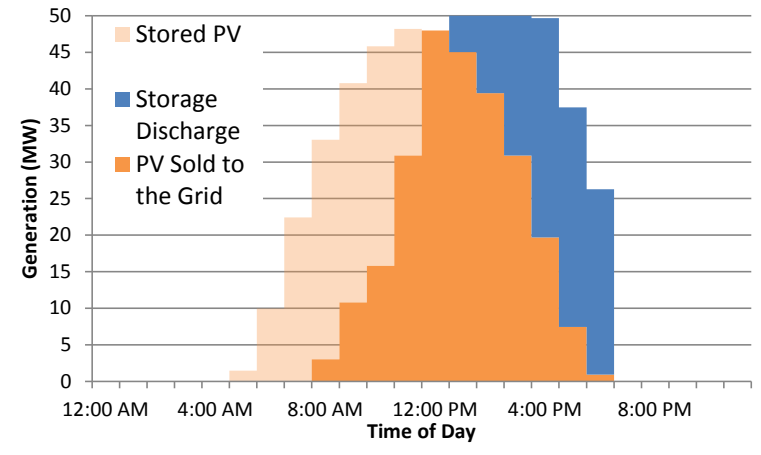

(b) Storage and PV Output

Figure 8. Optimal dispatch of a DC tightly coupled PV plus storage system (which stores only PV energy) on June 16 using 2014 price data from the SCE LAP

The energy revenues summed over an entire year are shown in Table 8 . We give results for three cases: independent, DC-coupled, and DC tightly coupled, noting that the independent case is roughly equal to the $\mathrm{AC}$ - coupled case as discussed previously. Table 8 reveals two significant results: a very small change in value associated with DC-coupling and a more significant reduction in value associated with DC tight coupling. The change in value associated with DC coupling is well below $1 \%$, with the small increase in value associated with avoided clipping 
largely canceling out the small decrease in value associated with non-optimal use of the storage. The annual loss in energy revenue associated with forcing the plant to store only solar energy (about $\$ 420,000$ ) is about $6 \%$ of the total. Table 8 also shows that the majority of the energy revenue is derived from PV generation. For the independent system, it is possible to isolate the sources of value, where about $14 \%$ is derived from the energy shifting value of storage, and $86 \%$ from the PV generation. For the coupled systems, it is more difficult to isolate the sources of value because they are increasingly interconnected, so we report only the combined value of the system.

Table 8. Energy Revenue from PV Plus Storage Systems with an ILR of 1.3, PV AC Rating of 50 MW, and Storage with 30 MW and 4 Hours of Capacity Using SCE 2014 Prices

\begin{tabular}{lccc} 
& $\begin{array}{l}\text { Independent/ } \\
\text { AC_Coupled }\end{array}$ & DC-Coupled & DC Tightly Coupled \\
\hline $\begin{array}{l}\text { Energy Revenue } \\
\text { (million \$) }\end{array}$ & $\begin{array}{c}6.95(0.98 \text { from storage } \\
\text { and 5.97 from PV) }\end{array}$ & 6.97 & 6.55 \\
$\begin{array}{l}\text { Change in Energy Revenue } \\
\text { due to coupling (million \$ / \%) }\end{array}$ & - & $0.02 /+0.3 \%$ & $\begin{array}{c}-0.42 /-6 \% \text { (compared } \\
\text { with DC-coupled) }\end{array}$ \\
\hline
\end{tabular}

\subsubsection{Capacity Value}

The second value component is capacity value. For our base case, using 2014 data, we use the estimated penetration of solar in California in that year (about 6\%). We identified three studies that estimate the incremental capacity credit of PV at 6\% solar penetration: 38\% Jones (2012), 48\% (Mills and Wiser 2012b), and 34\% (Denholm et al. 2016). This results in a range of capacity credits from $17 \mathrm{MW}$ to $24 \mathrm{MW}$, with an average of $20 \mathrm{MW}$, for the addition of $50 \mathrm{MW}$ of PV.

CAISO currently allows storage with 4-hours of discharge capacity to receive full capacity credit (CAISO 2017). An important part of maintaining high capacity credit for the storage system is the system's ability to charge from off-peak grid energy. This is how existing storage plants obtain high capacity credit and provide reliable service to utilities. A DC tightly coupled system cannot rely on grid electricity and we are unaware of any detailed study of the capacity credit of storage plants that can charge with only PV derived energy, so further analysis of the solar resource during high-demand days is required. Studies of concentrating solar power plants have shown that device with 4-hours of storage capacity can have very high capacity credits (Madaeni et al. 2013b), but additional analysis is required to verify this conclusion for PV plus storage.

The capacity credit is multiplied by the assumed cost of avoided conventional capacity. One estimate of the annualized financing and O\&M cost of a new combustion turbine in California is about $\$ 149 / \mathrm{kW}$-yr. However, estimates for other region are below $\$ 100 / \mathrm{kW}-\mathrm{yr}{ }^{8}$ For a storage system, these values are larger than the value of energy shifting/arbitrage. For example, the results in Table 8 indicate that the annual energy-shifting value of $30 \mathrm{MW}$ of independent storage is about $\$ 0.98$ million, or about $\$ 33 / \mathrm{kW}-\mathrm{yr}$, which is less than half the value of capacity.

\footnotetext{
${ }^{8}$ For example, one estimate of the cost of a new CT in Texas is $\$ 97 / \mathrm{kW}$-yr in Texas (Newell et al. 2014).
} 
Because our base case storage capacity is $30 \mathrm{MW}$, no decline in capacity value occurs owing to DC-coupling. The PV capacity credit of $20 \mathrm{MW}$ plus the storage capacity of $30 \mathrm{MW}$ is exactly equal to the inverter capacity of $50 \mathrm{MW}$. Had the PV capacity credit been higher (owing to a higher ILR, for example) or the storage capacity been higher, the DC-coupling would have resulted in lost capacity credit. This implies that as long as the PV capacity credit is greater than zero, the storage power capacity in a DC-coupled system should be sized to avoid exceeding the combined capacity credit of the individual PV and storage components.

\subsubsection{Benefit/Cost Ratio}

The benefit/cost ratio is calculated by dividing the annualized benefit (sum of the energy revenue and capacity value discussed in Section 4.1) by the annualized costs (discussed in Section 3.4). ${ }^{9}$ Figure 9 shows the results of the various cases. We must emphasize that the absolute values are speculative due to significant uncertainty of equipment costs, financing terms, and the cost of new capacity. Instead, our primary objective is to show how the values might change as a function of configuration and degree of coupling. In this example, we assume that the avoided cost of capacity is $\$ 149 / \mathrm{kW}$, equal to the financing and O\&M costs of a new combustion turbine (CT) from CAISO (2017). In all cases the 30\% ITC is applied to the PV portion of the system.

Figure 9 shows how each step of progressive coupling changes the $\mathrm{B} / \mathrm{C}$ ratio. The $\mathrm{PV}$ only case has the highest $\mathrm{B} / \mathrm{C}$ ratio. Adding independent storage reduces the $\mathrm{B} / \mathrm{C}$ ratio of the combined system reflecting its currently high cost, and because it is not eligible for the ITC. Moving from the individual PV plus storage configuration to the AC-coupled case slightly increases the B/C ratio because of the assumed reduction in BOS costs. In reality, this comparison is somewhat limited due to the fact that an independent storage system could be sited in a congested area, increasing the arbitrage value relative to the PV plus storage system which would likely be sited in a remote region. The $\mathrm{DC}$-coupled system results in a greater $\mathrm{B} / \mathrm{C}$ ratio due to the further reduction in cost, and because of the limited impact on revenue shown in Table 8. Requiring PVonly charging reduces the $\mathrm{B} / \mathrm{C}$ ratio due to reduced arbitrage revenue (also shown previous in Table 8). Finally, adding the ITC to the storage component significantly increases the $\mathrm{B} / \mathrm{C}$ ratio because of the substantially reduced cost of the battery.

\footnotetext{
${ }^{9}$ We assume that the energy and capacity values can be summed and does not represent double counting of the storage resource. This is based on the fact that periods of high prices are highly correlated with the demand peak.
} 


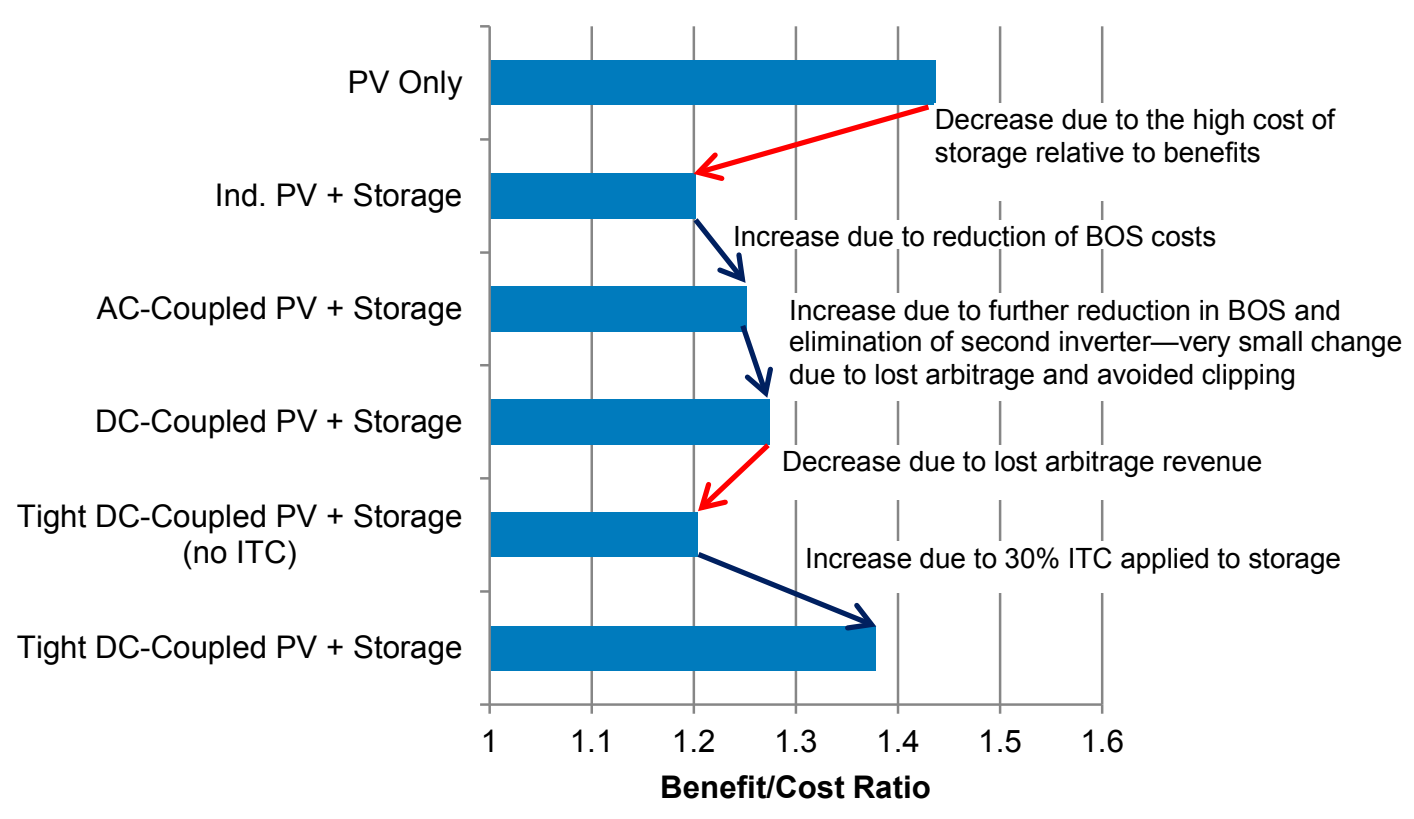

Figure 9. Base case benefit/cost ratio for PV and storage in California using 2014 electricity prices and 2016 estimated PV and battery costs

As discussed previously, these results provide an approximate indication of trends associated with coupling PV plus storage in California, with the actual technical and economic performance depending on many site specific factors. However, in this example, using historical cost and price data, the $\mathrm{B} / \mathrm{C}$ ratio of $\mathrm{PV}$ is significantly higher than storage, so adding storage to $\mathrm{PV}$ tends to reduce the $\mathrm{B} / \mathrm{C}$ ratio of the project overall. These results follow historical trends that have resulted in very limited deployment of PV plus storage systems. However, this analysis does not consider the impact of both increased PV penetration and reduction in storage costs, which is considered in the following section.

\subsection{Impact of Increased PV Penetration and Cost Reductions}

The previous results are all at a relatively low $\mathrm{PV}$ penetration of $6 \%$ of annual generation on the system, and use historical prices for both PV and storage. As both storage and PV costs continue to decrease, their $\mathrm{B} / \mathrm{C}$ ratio will continue to increase. However, increased PV penetration will also have a substantial impact, as the PV energy and capacity credit decrease.

Figure 10 shows the revenue from our simulated PV system using both historical (2014) electricity prices from the previous section, but also electricity prices from five different PV penetrations using simulated electricity price data for 2020 (Denholm et al. 2016). The price projections include several changes to the California grid including near-term expected retirements and an assumed carbon cost of $\$ 29.5 /$ ton (Brinkman et al. 2015). (The carbon cost is largely responsible for the increase in value from historical to projected prices). The figure shows the decline in PV energy revenue due the reduced marginal value of PV energy. 


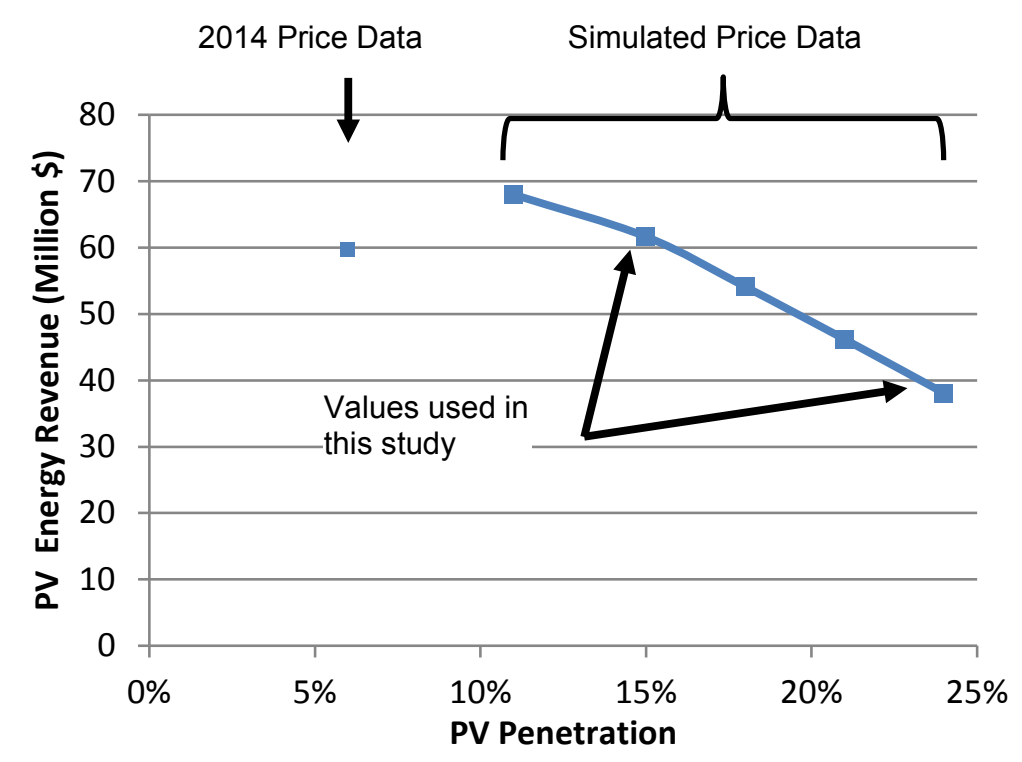

Figure 10. Energy revenue of PV as a function of PV penetration

To evaluate a range of possible PV penetration levels that could occur in California in the 2020 time frame, we evaluate a low (15\%) and high (24\%) scenario.

There is also a decline in capacity value, as increasing PV energy shifts the net-load peak to later in the day. Figure 11 shows the impact of PV on net load as a function of increasing PV penetration. When enough PV is added to meet $6 \%$ of California's annual load, the demand between 3 p.m. and 4 p.m. has been significantly reduced, but the net-load peak has been shifted two hours later. PV output in this period is much less, so PV's incremental capacity credit falls, and there is little reduction in the net-load peak beyond about $10 \%$ penetration. 


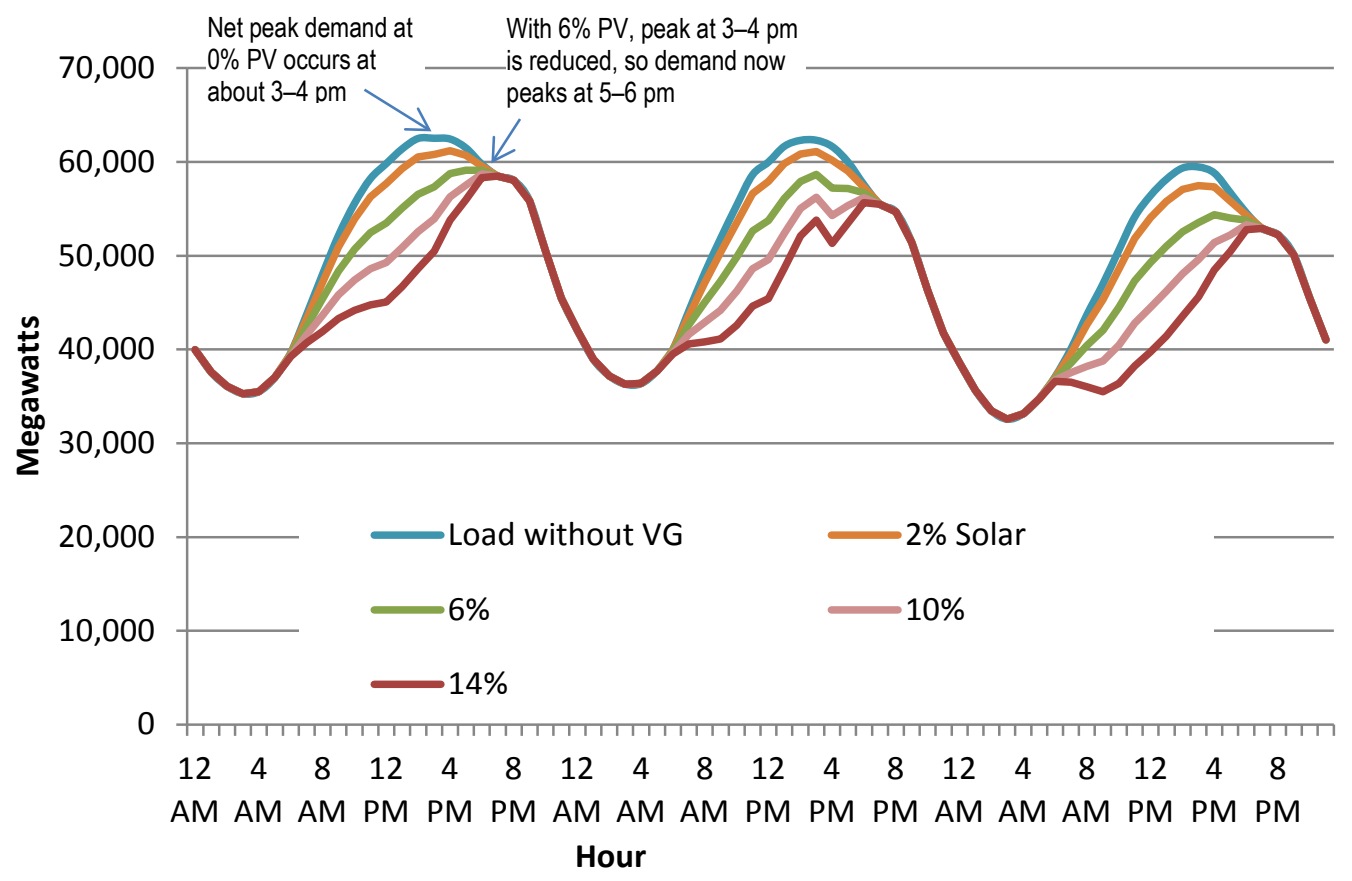

Figure 11. Impact of increased PV penetration on net load in California

Figure 12 shows the estimated capacity credit of PV as a function of penetration in California from three previous studies. For this study, we assume an $18 \%$ capacity credit at $15 \% \mathrm{PV}$ penetration and a $5 \%$ capacity credit at $24 \%$ penetration.

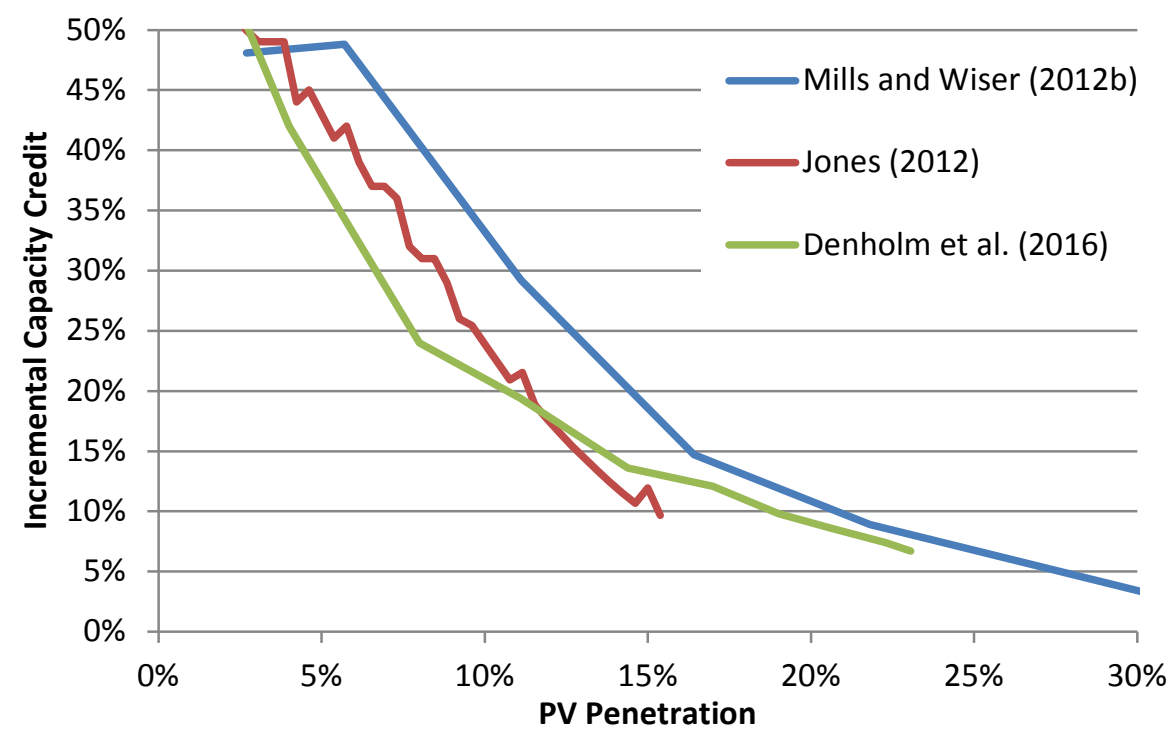

Figure 12. Decline in PV capacity credit using the capacity-factor approximation

The energy revenue and capacity value results can be combined to calculate a $\mathrm{B} / \mathrm{C}$ ratio for $\mathrm{PV}$ plus storage plants as a function of PV penetration. Figure 13 shows the $\mathrm{B} / \mathrm{C}$ ratios for our 2020 scenario under $15 \%$ and $24 \%$ PV penetrations. Figure 13(a) shows the results as the existing ITC would apply to the existing configurations. It shows the substantial drop in $\mathrm{PV} \mathrm{B} / \mathrm{C}$ ratio compared to the historical value, despite the decline in PV cost and continued ITC. This is due to the significant decline in $\mathrm{PV}$ value, which results in a $\mathrm{B} / \mathrm{C}$ ratio of less than 1 in the $24 \% \mathrm{PV}$ case. Adding storage increases the $\mathrm{B} / \mathrm{C}$ ratio because of the reduction in costs for storage. As in 
Figure 9, these results also show a small increase in B/C ratio with greater degrees of coupling, with the highest being the tight DC-coupled case due to the availability of the ITC.

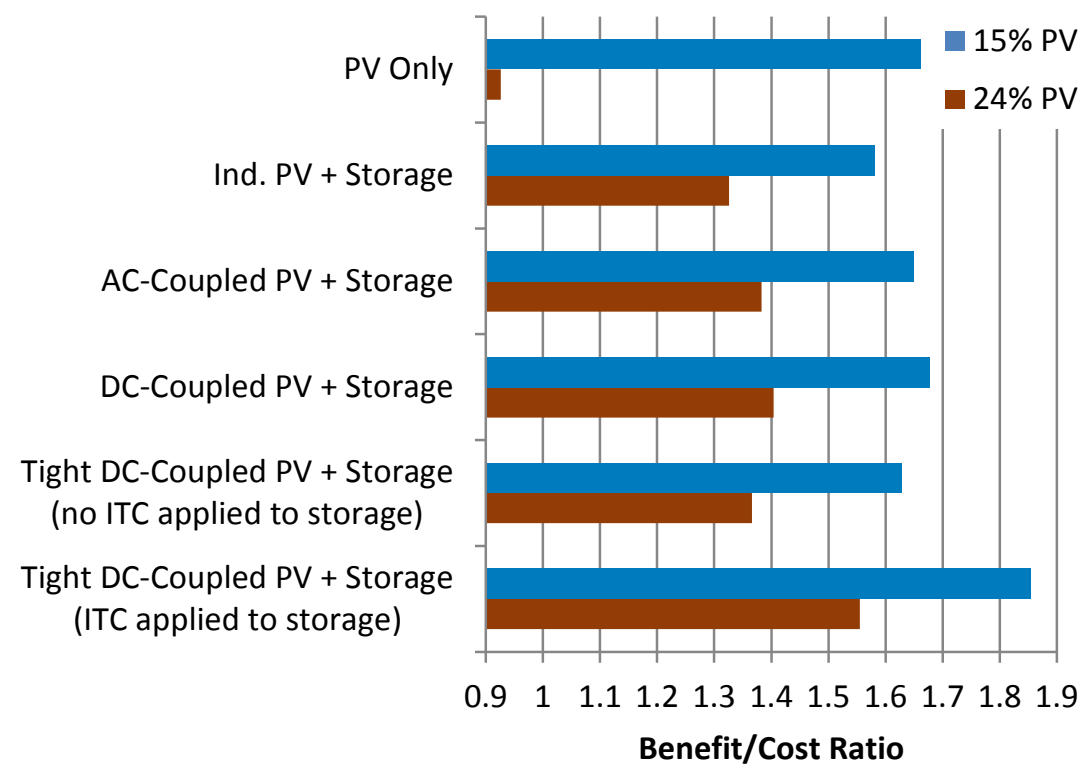

(a) assuming the $30 \%$ ITC applied to the PV system and to the storage system when charging only from solar

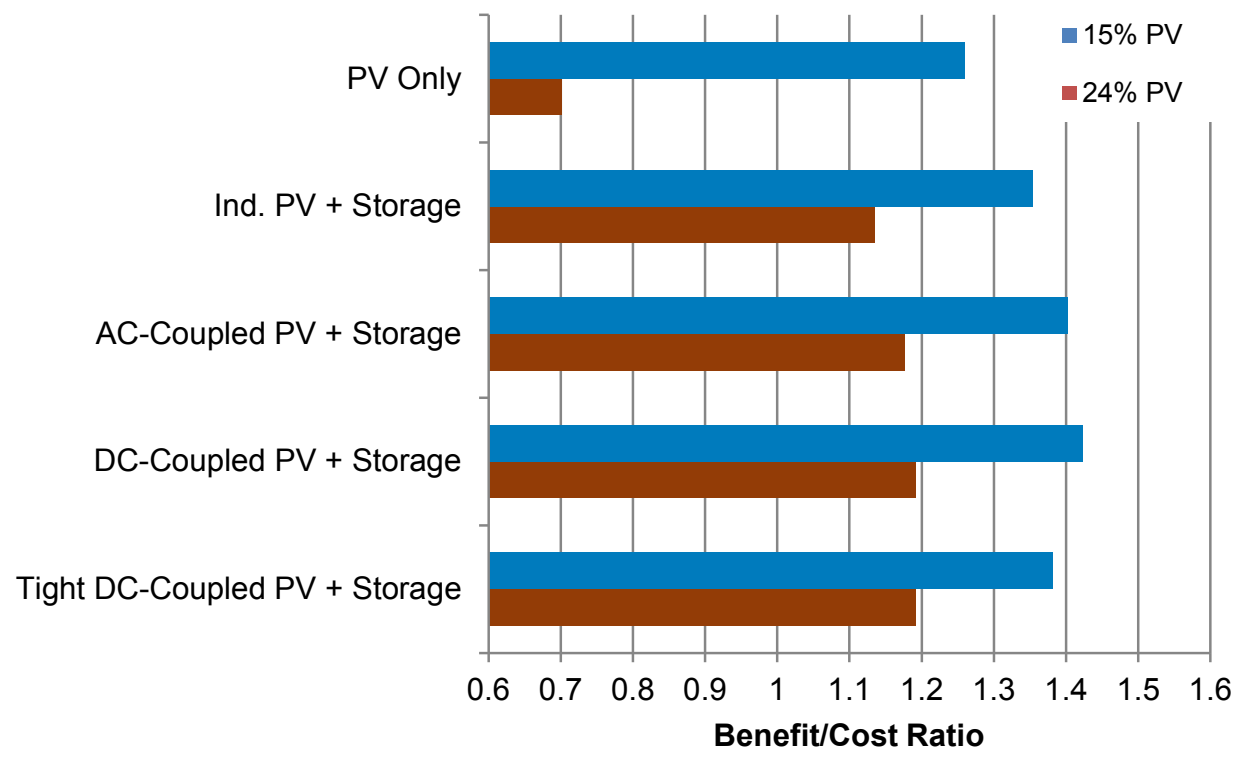

(b) assuming zero ITC for PV or storage

Figure 13. B/C ratio for PV plus storage plants in a 2020 scenario with two different levels of PV penetration and the (a) $30 \%$ ITC and (b) zero ITC 
Figure 13(b) shows the results with no ITC for either PV or storage. This results in a decline in $\mathrm{B} / \mathrm{C}$ ratio in all cases; however, the ratio remains above 1 for the $\mathrm{PV}$ plus storage systems. In this case, the highest $\mathrm{B} / \mathrm{C}$ ratio is for the $\mathrm{DC}$-coupled system with flexible charging, as the $\mathrm{DC}$ tightly coupled system suffers from lost revenue without the mitigating factor of the ITC seen earlier. However, in the $24 \%$ case, there is very little decrease in $\mathrm{B} / \mathrm{C}$ ratio for the tightly-coupled system, because at this level of PV penetration, a relatively large fraction of storage charging is derived from PV. These results follow previous analysis showing that declining PV value can be mitigated with energy storage and can maintain the ability to cost-effectively integrate large amounts of PV (Mills and Wiser 2015; Denholm et al. 2016). 


\section{Conclusions}

PV plus storage systems can have multiple configurations, depending on the degree of coupling and the sizing of components. Evaluating a specific configuration, from the system owner's perspective, requires calculating the net value of the system via a detailed accounting of costs and benefits. Simple metrics such as LCOE cannot capture the differences in net value between different configurations or the differences between PV plus storage and traditional fossil generation. Our analysis illustrates one method to calculate the net value of a solar plus storage system using a benefit/cost ratio metric to evaluate the attractiveness of various PV plus storage configurations under a range of conditions.

We find that there are cost-benefit tradeoffs among the various PV plus storage configurations we examined. Independent systems have the highest cost, because separate siting of PV and storage components increases BOS costs compared with the costs of AC- and DC-coupled systems. Alternatively, independent systems also enable storage to be sited within congested urban areas, although we do not account for the resulting benefit in our analysis. DC-coupling introduces a complex set of impacts on net value, which include both increasing energy revenue by avoiding clipped energy and decreasing energy revenue value by placing some constraints on storage dispatch associated with a shared inverter.

Our analysis demonstrates how these cost-benefit tradeoffs can be quantified across a set of cases. Both AC- and DC-coupled systems have the potential to provide a small but measurable increase in $\mathrm{B} / \mathrm{C}$ ratio compared with the independent system across a wide range of avoidedcapacity costs. However, evaluating these systems requires understanding the size of the grid connection and a more detailed analysis of non-hardware related costs including siting, permitting, and interconnection costs that can be avoided by co-locating the storage with PV. We also evaluate the impact of a system that stores only solar energy. This configuration incurs a measurable loss in value to the owner-and to society more broadly — because of the nonoptimal dispatch of the storage component. However, the loss of value to the owner is much less than the reduction in cost associated with current incentives via the ITC. This produces the highest overall value of the various configurations we considered.

Our findings indicate that — when storage is appropriately sized — co-locating and sharing components can increase the net value of a PV plus storage system. However, this conclusion that coupling can increase the overall value of a solar plus storage system depends on a number of assumptions. First, these results are for a specific location and one specific combination of PV and storage component sizes. Additional analysis is needed to evaluate the sensitivity of these results to alternative configurations, including tracking PV systems, different inverter loading ratios and in other parts of the country. Second, we do not consider the potentially significant benefits associated with deploying storage in congested areas. Storage has a much smaller footprint than PV, and it can be deployed to defer new investments in transmission and distribution capacity and to replace peaking capacity in urban areas. It is difficult to realize this benefit if storage is combined with large, utility-scale PV systems. Third, we choose a storage power capacity that is considerably smaller than the PV capacity. Storage power capacity must be considered carefully to avoid exceeding the inverter capacity during periods that determine the capacity credit of the overall system 
Finally, the entire concept of "coupling" PV and storage warrants additional discussion and analysis among the broader engineering and policy stakeholder communities. In our analysis, we find that systems that charge only with PV have the highest benefit to the developer because of the ITC. We also suggest that this configuration may not provide the highest value to the system as a whole. In addition to storing PV when other, lower-cost resources are available, this configuration incurs the risk of depending on a single source for charging the storage, thus increasing the probability that stored energy may be unavailable during periods of peak demand. Operating a PV plus storage system in a tightly coupled manner also decreases the overall efficiency of the power system and deviates from the normal manner in which grid assets are used to minimize overall system costs and maximize societal benefits. As the ITC is reduced or expires, the incentive to operate in this mode may be reduced. Alternatively, PV-only charging may continue to be incentivized, as it creates an easy method to create a "dispatchable" renewable resource from a contractual and accounting standpoint. The benefits of more easily accounting for the renewable generation and emissions avoidance from this configuration needs to be compared to the potentially reduced economic benefits. Ultimately, a PV plus storage power plant represents a new class of generation resource that needs to be better evaluated in terms of system planning and operation to maximize its benefits as continued reductions in price drive increased deployment. 


\section{References}

Amelin, Mikael. 2009. "Comparison of Capacity Credit Calculation Methods for Conventional Power Plants and Wind Power." IEEE Transactions on Power Systems (24:2).

Ardani, Kristen, Eric O'Shaughnessy, Ran Fu, Chris McClurg, Joshua Huneycutt, and Robert Margolis. 2017 Installed Cost Benchmarks and Deployment Barriers for Residential Solar Photovoltaics with Energy Storage: Q1 2016. Golden, CO: National Renewable Energy Laboratory. NREL/TP-7A40-67474. http://www.nrel.gov/docs/fy17osti/67474.pdf.

Bolinger, Mark, and Joachim Seel. 2016. Utility-Scale Solar 2015: An Empirical Analysis of Project Cost, Performance, and Pricing Trends in the United States. Berkeley, CA: Lawrence Berkeley National Laboratory. LBNL- 1006037. https:/emp.lbl.gov/sites/default/files/lbnl1006037 report.pdf.

Brinkman, Gregory, Jennie Jorgenson, Ali Ehlen, and James H. Caldwell. 2016. California 2030 Low Carbon Grid Study: Analysis of a 50\% Emission Reduction in California. Golden, CO: National Renewable Energy Laboratory. NREL/TP-6A20-64884. http://www.nrel.gov/docs/fy16osti/64884.pdf.

CAISO 2017. “2016 Annual Report on Market Issues and Performance.” May 2017.

CEC (California Energy Commission). 2014. California electricity statistics and data. Sacramento, CA. Accessed January 30, 2014

Denholm, Paul Joshua Novacheck, Jennie Jorgenson, and Matthew O'Connell. 2016. Impact of Flexibility Options on Grid Economic Carrying Capacity of Solar and Wind: Three Case Studies. Golden, CO: National Renewable Energy Laboratory. NREL/TP-6A20-66854. http://www.nrel.gov/docs/fy17osti/66854.pdf.

Denholm, Paul, Victor Diakov, and Robert Margolis. 2015. The Relative Economic Merits of Storage and Combustion Turbines for Meeting Peak Capacity Requirements under Increased Penetration of Solar Photovoltaics. Golden, CO: National Renewable Energy Laboratory. NREL/TP-6A20-64841. http://www.nrel.gov/docs/fy15osti/64841.pdf.

Eichman, J., Townsend, A., \& Melaina, M. (2016). Economic Assessment of Hydrogen Technologies Participating in California Electricity Markets. Golden, CO: National Renewable Energy Laboratory. NREL/TP-5400-65856. http://www.nrel.gov/docs/fy16osti/65856.pdf.

Fu, Ran, David Feldman, Robert Margolis, Michael Woodhouse, and Kristen Ardani. Forthcoming. U.S. Solar Photovoltaic System Cost Benchmark: Q1 2017. Golden, CO: National Renewable Energy Laboratory. NREL/TP-6A20-68925.

GTM Research. (2016). “Grid-Scale Energy Storage Balance of Systems 2015-2020: Architectures, Costs and Players"

GTM Research, and SEIA (Solar Energy Industries Association). U.S. Solar Market Insight Q2 2015. September 2015.

Jones, R. 2012. "Diversity Benefit of Solar and Wind with Increasing Market Penetration." Intersolar North America. July 12. 
Lai, Chun Sing, and Malcolm D Mcculloch. 2016. Levelized Cost of Energy for PV and Grid Scale Energy Storage Systems.

Mills, Andrew, and Ryan Wiser. 2012a. Changes in the Economic Value of Variable Generation at High Penetration Levels: A Pilot Case Study of California. Berkeley, CA: Ernest Orlando Lawrence Berkeley National Laboratory. LBNL-5445E. http://emp.lbl.gov/sites/all/files/lbnl5445e.pdf.

. 2012b. An Evaluation of Solar Valuation Methods Used in Utility Planning and Procurement Processes. Berkeley, CA: Ernest Orlando Lawrence Berkeley National Laboratory. LBNL-5933E. http://emp.lbl.gov/sites/all/files/lbnl-5933e_0.pdf.

- 2015. "Strategies to Mitigate Declines in the Economic Value of Wind and Solar at High Penetration in California." Applied Energy 147(2015):269-278.

Madaeni, Seyed Hossein, Ramteen Sioshansi, and Paul Denholm. 2013a. "Comparing Capacity Value Estimation Techniques for Photovoltaic Solar Power," IEEE Journal of Photovoltaics 3(1) 407-415.

—. 2013b. "Estimating the Capacity Value of Concentrating Solar Power Plants with Thermal Energy Storage: A Case Study of the Southwestern United States" IEEE Transactions on Power Systems 28(2) 1205-1215.

NERC (North American Electric Reliability Corporation). 2011. "Methods to Model and Calculate Capacity Contributions of Variable Generation for Resource Adequacy Planning." http://www.nerc.com/docs/pc/ivgtf/IVGTF1-2.pdf.

Newell, Samuel A., Kathleen Spees, Johannes P. Pfeifenberger, Ioanna Karkatsouli, Nick Wintermantel, and Kevin Carden. 2014. Estimating the Economically Optimal Reserve Margin in ERCOT. Prepared for the Public Utility Commission of Texas. Cambridge: The Brattle Group. http://www.brattle.com/system/news/pdfs/000/000/613/original/Estimating the Economically Optimal_Reserve_Margin_in_ERCOT.pdf?1391445083

Nourai, Ali, V. I. Kogan, and Chris M. Schafer. 2008. "Load Leveling Reduces T\&D Line Losses." IEEE Transactions on Power Delivery 23:2168-2173.

NREL (National Renewable Energy Laboratory). 2017. "Federal Tax Incentives for Battery Storage Systems.” Golden, CO: National Renewable Energy Laboratory. January 2017. NREL/FS-7A40-67558. http://www.nrel.gov/docs/fy17osti/67558.pdf.

Nykvist, Björn, and Måns Nilsson. 2015. "Rapidly Falling Costs of Battery Packs for Electric Vehicles." Nature Climate Change 5:329-332.

PGE (Portland General Electric). 2016. Integrated Resource Plan.

Sioshansi, Ramteen, Seyed Hossein Madaeni, and Paul Denholm. 2014 “A Dynamic Programming Approach to Estimate the Capacity Value of Energy Storage." IEEE Transactions on Power Systems 29(1) 395-403. 


\section{Appendix: Financial Assumptions}

Table A-1. Financial Assumptions

\begin{tabular}{lcc}
\hline & $\begin{array}{c}\text { PV } \\
\text { Components }\end{array}$ & $\begin{array}{l}\text { Battery } \\
\text { Components }\end{array}$ \\
\hline Inflation Rate & $2.5 \%$ & $2.5 \%$ \\
Economic Lifetime (Years) & 20 & 15 \\
Interest Rate - Nominal & $4.4 \%$ & $4.4 \%$ \\
Calculated Interest Rate - Real & $1.9 \%$ & $1.9 \%$ \\
Interest During Construction - Nominal & $4.4 \%$ & $4.4 \%$ \\
Rate of Return on Equity - Nominal & $9.5 \%$ & $9.5 \%$ \\
Calculated Rate of Return on Equity - Real & $6.8 \%$ & $6.8 \%$ \\
Debt Fraction & $40.0 \%$ & $40.0 \%$ \\
Tax Rate (Federal and State) & $40.0 \%$ & $40.0 \%$ \\
WACC - Nominal & $6.7 \%$ & $6.7 \%$ \\
WACC - Real & $4.1 \%$ & $4.1 \%$ \\
Depreciation Period (Years) & 5 & 7 \\
Construction Finance Factor & 1.013 & 1.009 \\
Present Value of Depreciation & 0.837 & 0.805 \\
Project Finance Factor & 1.233 & 1.233 \\
Capital Recovery Factor (CRF) - Nominal & $9.0 \%$ & $10.7 \%$ \\
Capital Recovery Factor (CRF) - Real & $7.4 \%$ & $9.1 \%$ \\
\hline
\end{tabular}

